\title{
PROFESSOR TAMÁS PÓCS THE RECORD OF HIS 80 YEARS
}

\author{
SÁNDOR ORBÁN \& ERIKA PÉNZES-KÓNYA
}

Sándor Orbán \& Erika Pénzes-Kónya, Department of Botany, Károly Eszterházy College, H-3300 Eger, 6th Leányka street, Hungary; e-mail: orban@ektf.hu

The eminent Hungarian botanist and bryologist Professor Tamás Pócs was born in Budapest on 6 August 1933. He attended the Reformation Secondary School of Budapest, famous for its outstanding professors, and here his serious interest in botany began. At age 15 he became a member of the Hungarian Botanical Society. In 1951 he took part in the vegetation mapping course of the Hungarian Academy of Sciences in Vácrátót.

In 1951 he applied to study biology and chemistry at Eötvös Loránd University, Budapest. In his second year of studies he entered a special botanical science course under Professor Rezső Soó, who invited Tamás to work in his Botany Department after graduation in January 1956. However, he chose the Herbarium of the Natural History Museum in Budapest as his place of work, and donated his plant collection consisting of 8,000 specimens to the Herbarium upon taking the job there.

He published his first paper in 1954, and cowrote the manuscript of his first book in 1955 , both while still a student. From 1955 on he explored botanically interesting areas of Transylvania and the southern Carpathians. He investigated the vegetation of western Hungary and, together with other young botanists, made vegetation maps of the area which were published as the book Vegetationsstudien in Orség in 1958. In 1959 he received his doctoral degree summa cum laude, and in 1967 achieved the title Candidate of Sciences (CSc), now PhD.

Keenly interested in educating others, he applied for the post of Head of the Department of
Botany of the Teachers' Training College in Eger in 1963. During his 18 years at that post, Professor Pócs he developed the department into a strong educational and research unit. His basic concept was to set up, with his colleagues, a research center attached to a cryptogam herbarium, which is now one of Central Europe's biggest herbaria, holding 250,000 specimens, mainly tropical bryophytes.

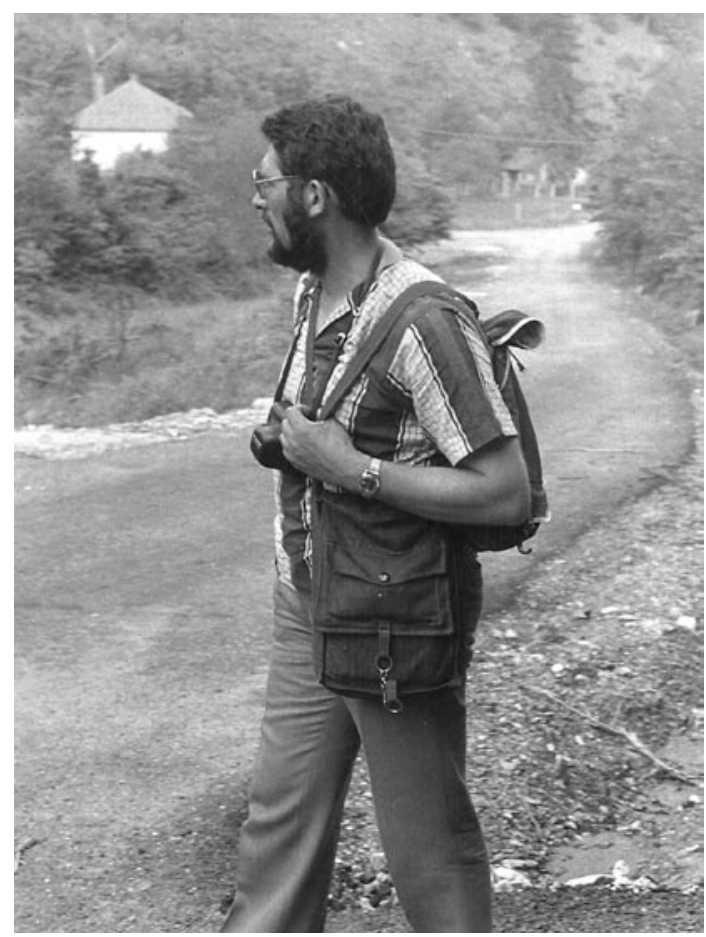

Fig. 1. Tamás Pócs, 1978. Photo J. Váňa. 


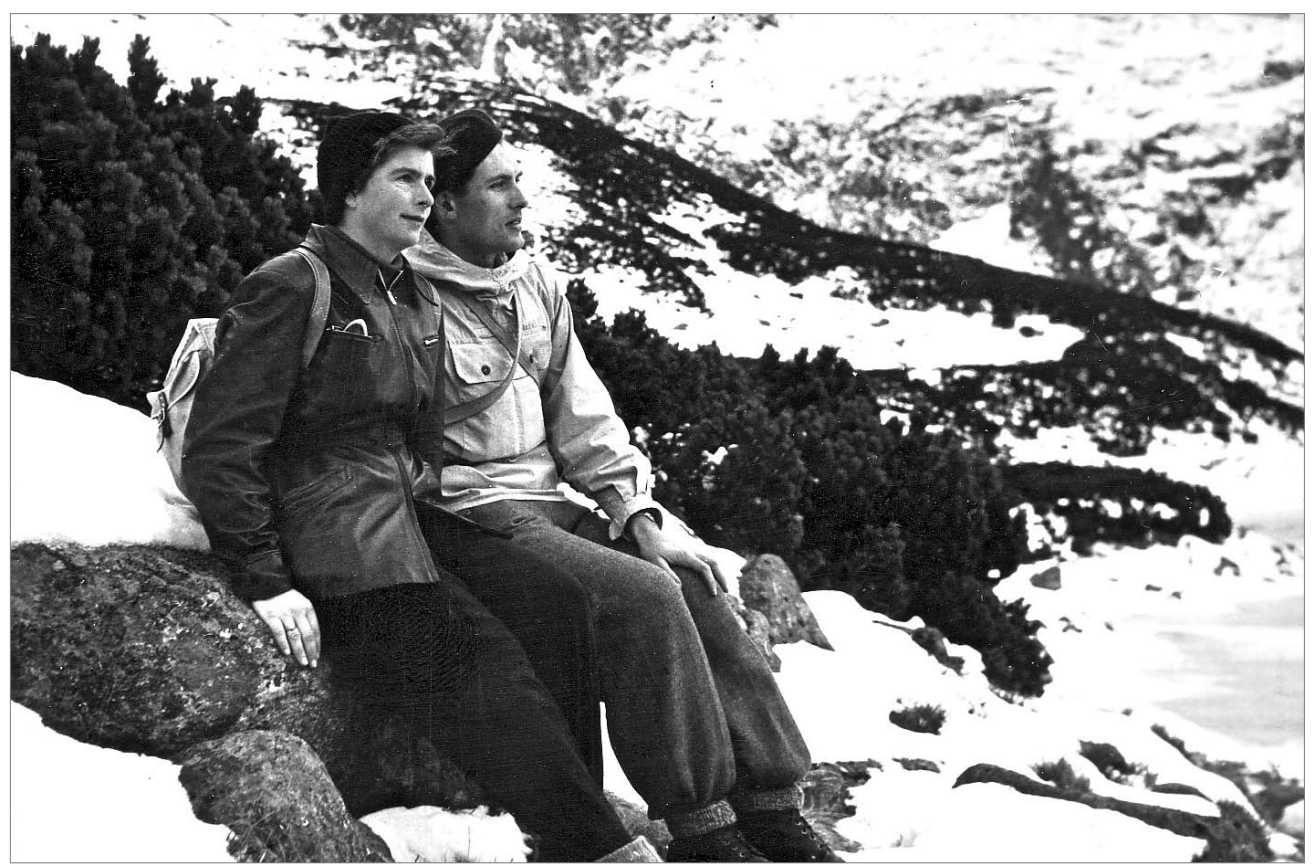

Fig. 2. Anna Medwecka-Kornaś and Tamás Pócs in the Tatra Mts, Poland, 1959 (courtesy of A. Medwecka-Kornaś).

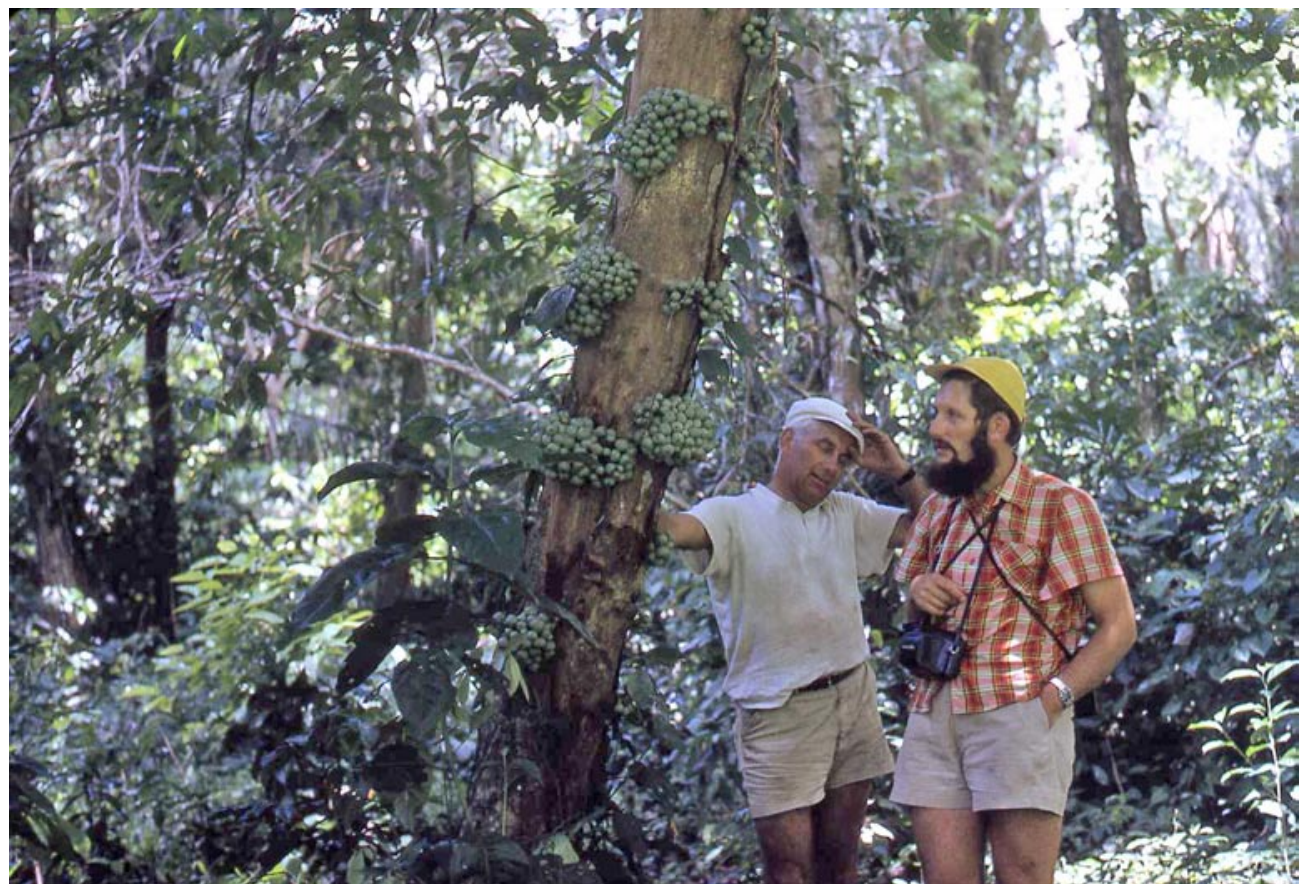

Fig. 3. Jan Kornaś and Tamás Pócs in tropical forest at the foot of Uluguru Mts, Tanzania, 1973. Photo. A. Medwecka-Kornaś (courtesy of A. Medwecka-Kornaś). 


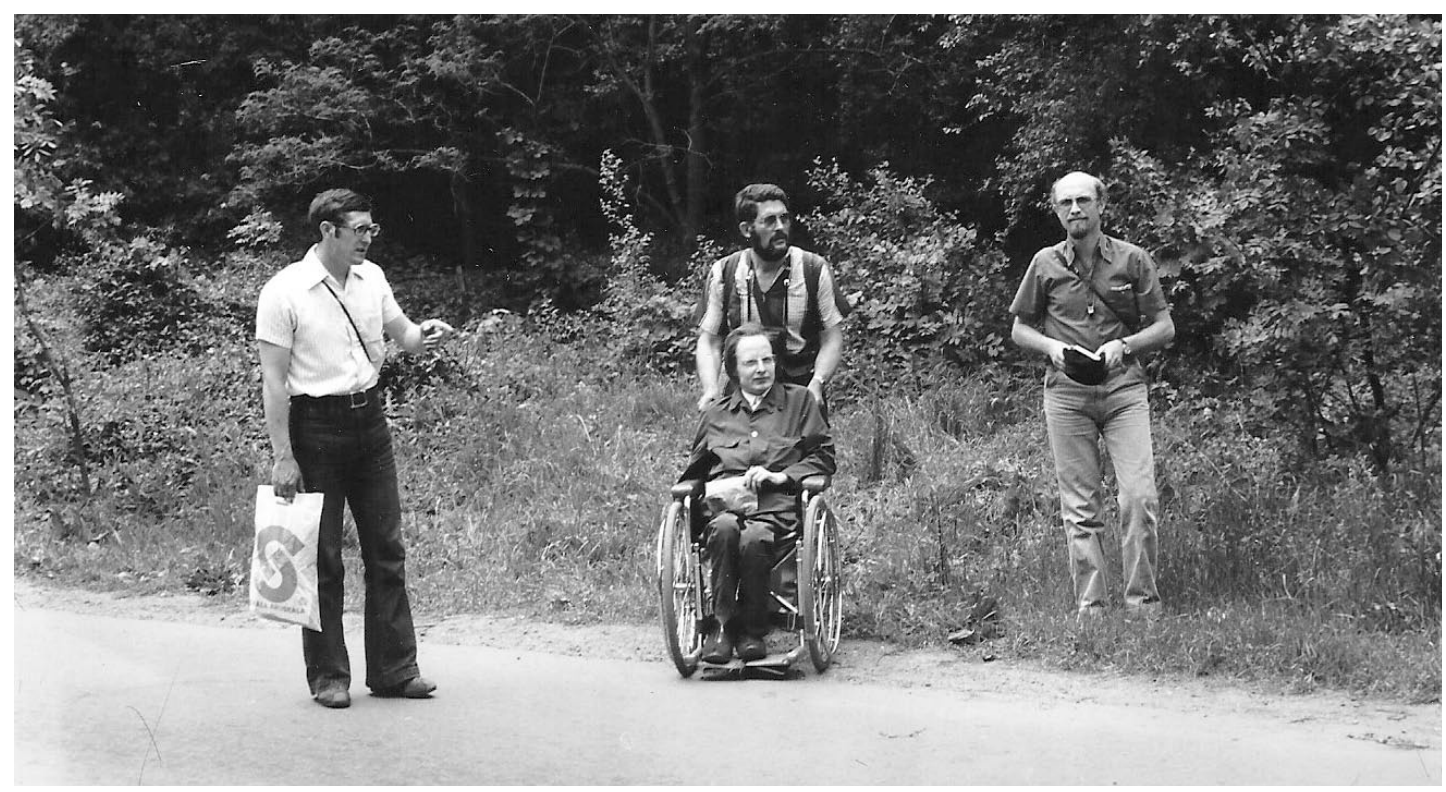

Fig. 4. On an excursion after the $1^{\text {st }}$ Central and East European Bryological Working Group (CEEBWG) meeting in Eger, Hungary, 1978 [from left: Sándor Orbán, Riclef Grolle (in wheelchair), Tamás Pócs, and S. Robbert Gradstein]. Photo J. Váňa.

Many Hungarian and foreign scientists visit the herbarium to examine its materials. Another important activity of the herbarium is exchange of specimens; the collection includes a wealth of specimens sent from places never visited by any Hungarian bryologists. The Department of Botany (now divided into the Department of Botany and the Department of Plant Physiology) employs the latest research methods to study the taxonomy, ecology and physiology of cryptogamic plants.

Professor Pócs interest turned to tropical botany early in his career. He went on an expedition to Vietnam lasting a month and a half in 1963, followed by a three-month expedition in 1965-1966. The richness and variety of tropical vegetation fascinated him and determined his further lines of research. His work in Vietnam added thousands of specimens to a number of Hungarian and foreign plant and animal collections.

These first tropical expeditions were followed by many other trips. His studies in Africa have occupied the longest period of his work. He has also visited Latin America and Asia, doing research or collecting plants and animals in about

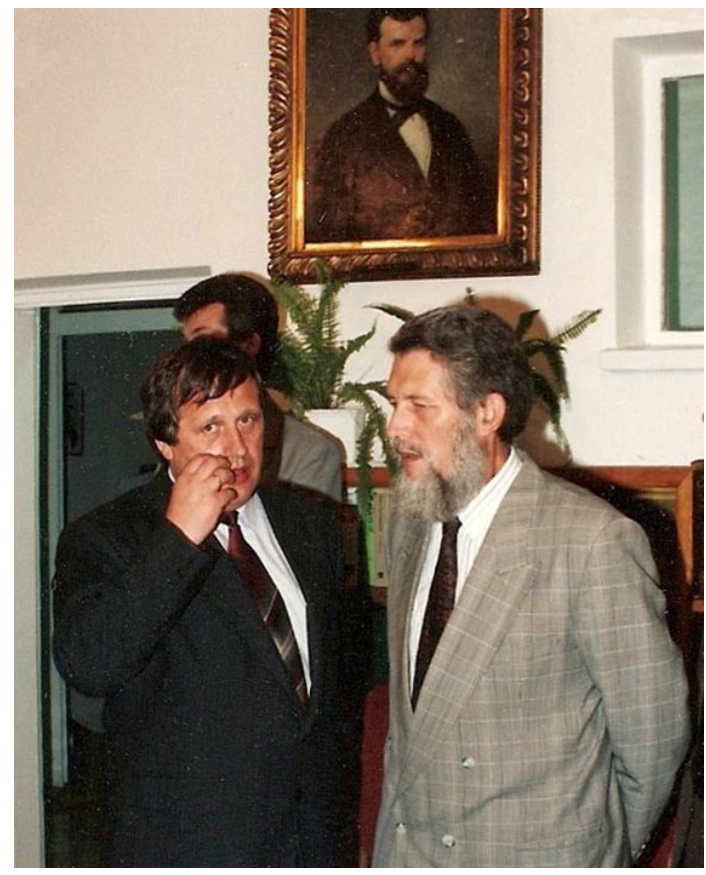

Fig. 5. Tamás Pócs (right) and Ryszard Ochyra (left) during meeting in the W. Szafer Institute of Botany, Polish Academy of Sciences, Kraków, 1991 (photo from Erika Pénzes-Kónya). 


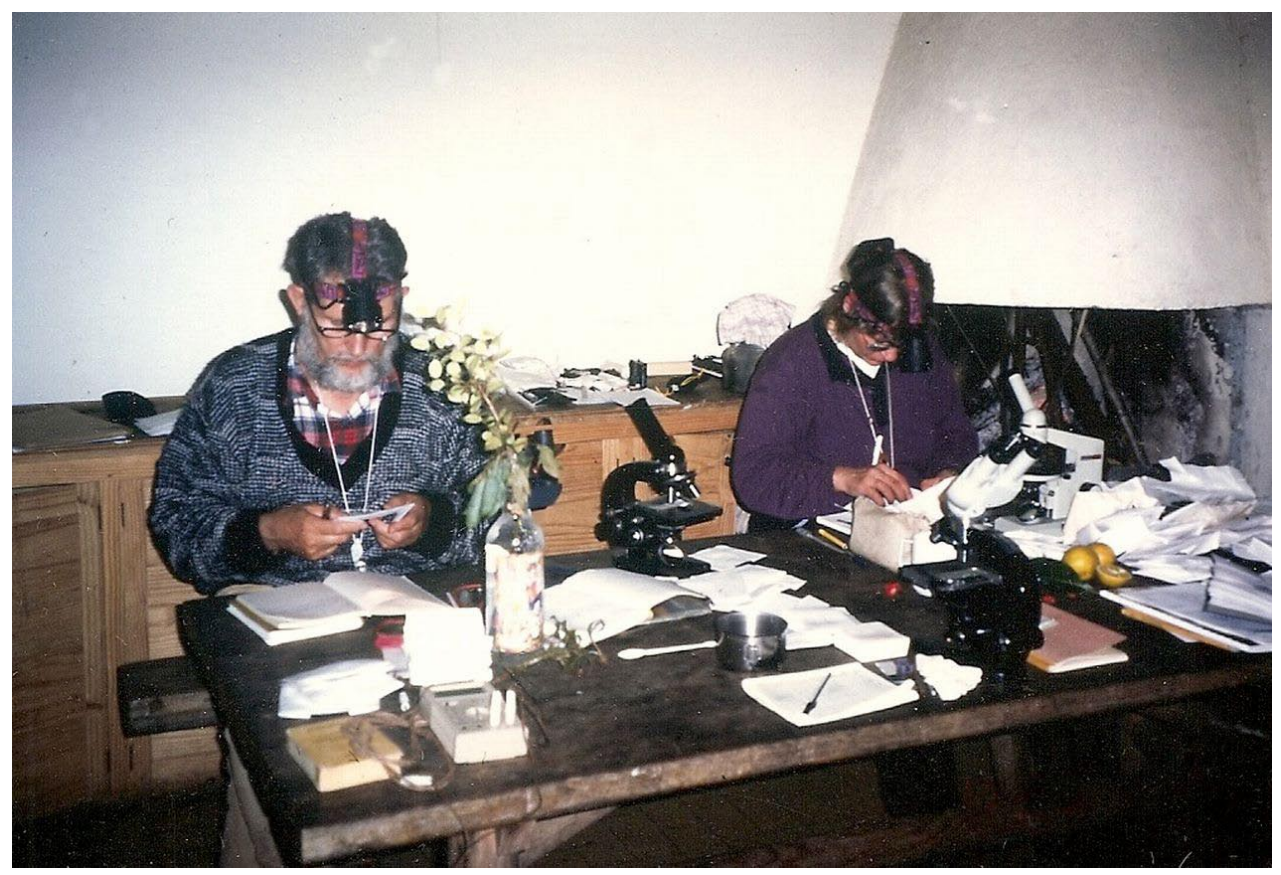

Fig. 6. Tamás Pócs and Gabriella Kis preparing bryophytes collected on the Isle of Réunion, 1996. Photo András Szabó (photo from Erika Pénzes-Kónya).

25 tropical countries. Recently he studied Australia and Oceania. He has collected about 200,000 plant specimens and hundreds of animal samples, and has done forest ecology research and vegetation mapping. He has participated in numerous projects, including Bryologia Africana, Bryoflora of Uganda, Flora of Brasil, Flora de Cuba, Flora Neotropica, Bryophytes West Melanesia, and Flora of Australia. As a professor in Africa he took part in ecological, conservation and biodiversity studies of the Swedish Usambara Integrated Rain Forest Project and in the ecological monitoring program of the Ngorongoro Conservation area.

He was the first in the world to examine the correlation between epiphytic biomass and its water uptake capacity; the works reporting those results are among his most frequently cited publications. These quantitative studies showed that epiphytic biomass may reach 14 tons/ha and can take up 50,000 liters of water from rainfall and evaporate it slowly to the environment. This is much more than the water taken up by the whole canopy. It is supplemented by fog precipitation in the cloud zone. These findings are of huge importance; they mean that epiphytic vegetation can regulate precipitation in the cloud zone of tropical watershed mountains, maintaining the continuity of flow to the water reservoir network through the year and thus maintaining the water supply in streams and rivers in the dry season, providing a stable source of water for consumption, irrigation and energy production.

There was a new challenge for him in Tanzania when an opening for foreign teachers was announced at the University of Tanzania. He landed the job and became Senior Lecturer in Crop Botany, a post he held for four years (1969-1973) as one of the founders of the Agricultural Faculty.

Returning to Eger, in addition to teaching he synthesized the results of his research in Tanzania and used this material to write his doctoral thesis, which was accepted in 1977. In 1978 he was invited to the Botanical Research Centre of the Hungarian Academy of Sciences in Vácrátót as head of the Botanical Garden and scientific advisor. During these years he had opportunities to 
join expeditions to Cuba and to Tanzania where he took part in the Rain Forest Program within the framework of Swedish-Hungarian-Tanzanian cooperation.

In 1985 he was invited to the Department of Forest Biology of the Tanzanian University of Agriculture as Professor of Forest Biology, which title was conferred by the Norwegian government supporting the university. His Tanzanian research extended to all of northeast Tanzania. He became a consultant to the Norwegian Agency for Development Cooperation (NORAD), and the results of his research were published in a local publication of the WWF, co-authored with Jon Lovett.

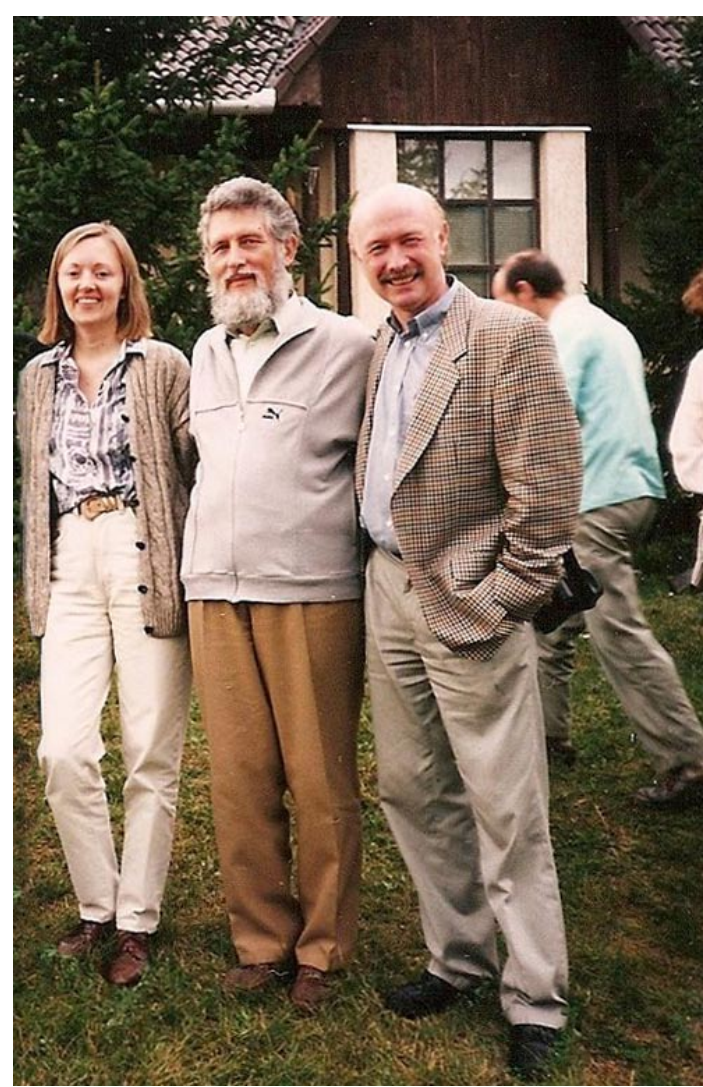

Fig. 7. International Association of Bryologists (IAB) meeting and International Conference on 'Foliicolous Cryptogams' held in Eger, Hungary, 1995. Participants at Tamás Pócs' house in Felsőtárkány (from left: Andrea Lücking, Tamás Pócs, S. Robbert Gradstein. Photo: Sarolta Pócs (photo from Erika Pénzes-Kónya).

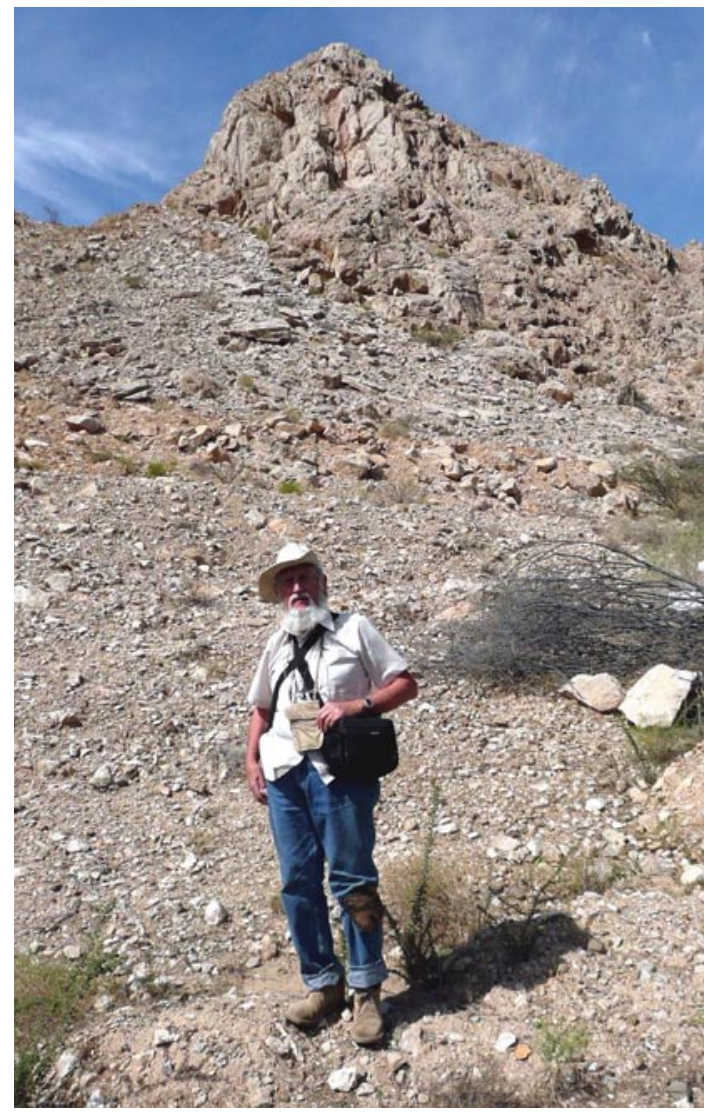

Fig. 8. Tamás Pócs in the Dubai Dessert, United Arab Emirates, 2009. Photo S. Pócs.

After returning from Tanzania (1989) he worked for two years in Vácrátót and then went to Eszterházy Károly College in Eger (1991) as a professor. He headed the Department of Botany and was also Vice President of the college for several years. In Eger he established the Bryological Research Group of the Hungarian Academy of Sciences and led it between 1999 and 2003.

During his years in Vácrátót he lectured at Eötvös Loránd University of Budapest (ELTE) and at the University of Agriculture in Gödöllö, and became a professor at Eötvös Loránd University. Recently he has been at Eszterházy Károly College as Professor Emeritus.

Professor Pócs became an external member of the Norwegian Academy of Sciences in 1992. He 


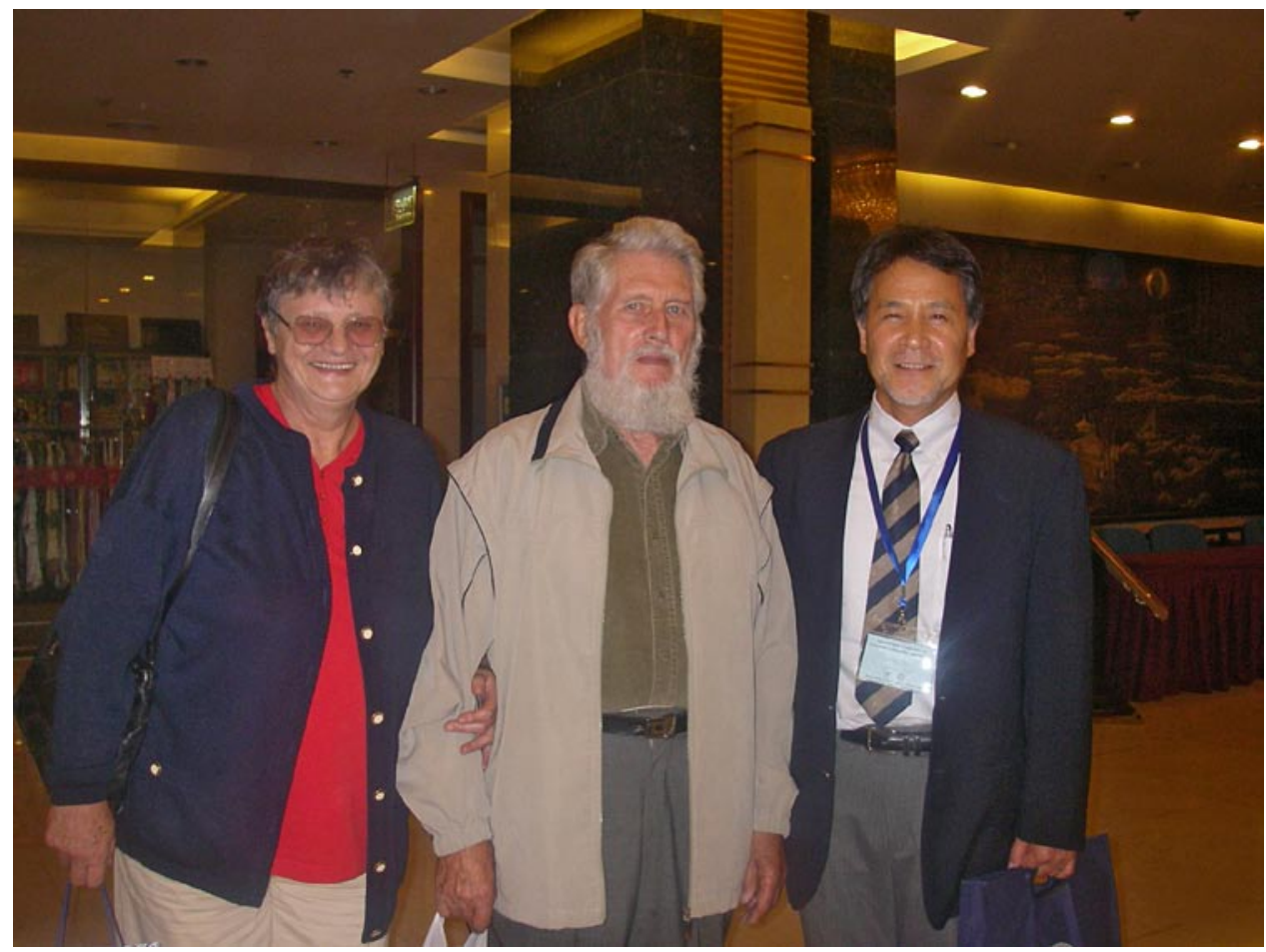

Fig. 9. Sarolta Pócs, Tamás Pócs, and Masanobu Higuchi at reception held at Zhejiang University, Hangzhou, Zhejiang Province, China, 16 October 2010. Photo Qin Zuo (courtesy of Masanobu Higuchi).

was elected corresponding member of the Hungarian Academy of Sciences in 1995, and member in 2001.

Professor Pócs has always placed great stress on educating young talent, not only teaching undergraduate and postgraduate courses but also lecturing and leading special courses at different universities (Helsinki, Nairobi, Merida, Kuala Lumpur). He has advised 15 doctoral students, four of whom are professors now. He has been to 45 countries including Canada, Japan, Venezuela and Australia, mainly for collecting and research expeditions. There are former students of his in almost all of those countries.

His achievements include $c a 400$ publications (see BiBliogRAPHY OF TAMÁS PÓCS), about 3,000 citations, and lectures at 25 international congresses.

The taxa new for science which he described or diagnosed include 13 vascular plants, 204 bryophytes and one snail taxon. On the basis of materials collected by Professor Pócs about 350 new taxa of vascular plants, bryophytes, lichens, fungi, snails, insects and acari have been described by other researches (see Orban 2003 and attached Lists) Many taxa bear his name, such as Pocsia Vežda (lichen), Pocsiella Bizot (bryophyte), Pocsia and Pocsoppia Mahunka (acari), genera new for science (see list).

Professor Pócs has received 11 high honors, among them the Szent-Györgyi Albert Prize (1996), the Pro Natura Prize (2001), the Szilárd Leó Scholarship (2003) and the Order of Merit of the Hungarian Republic, Officer's Cross (2010).

His service to international and Hungarian scientific societies includes being a founder member and Vice President of the International Association of Bryologists (1981-1987), President of the Hungarian Biological Society from 1991 to 1994, and President of the Botanical Committee of the Hungarian Academy of Sciences from 1993 to 1996. He was elected Honorary Vice President of 


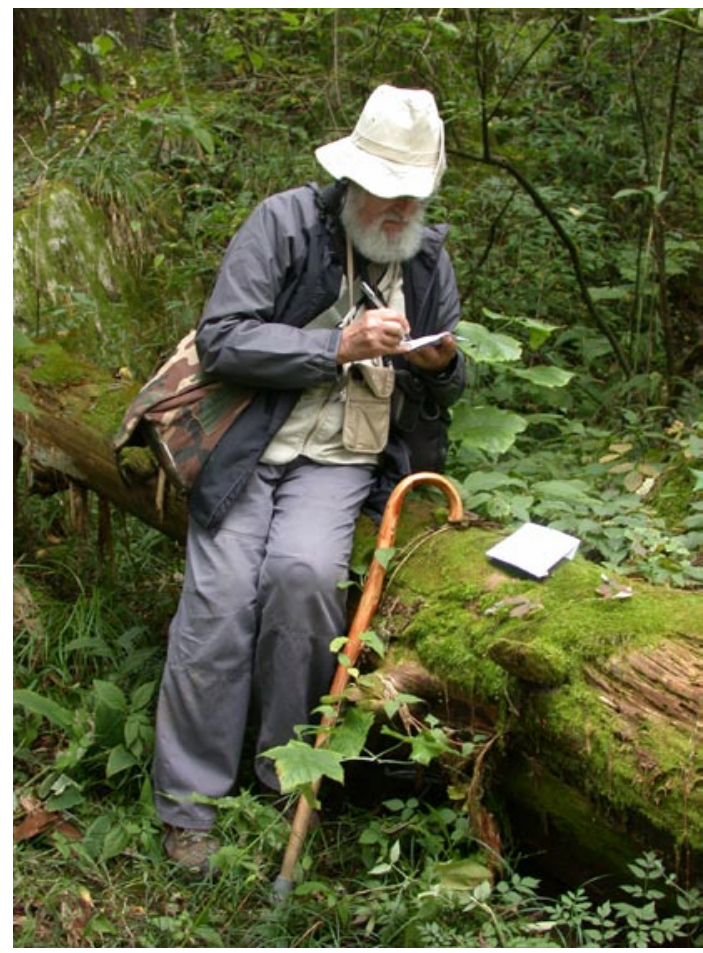

Fig. 10. Tamás Pócs in the field at Tianmushan, Linan County, Zhejiang Province, China, 19 October 2010. Photo M. Higuchi.

the XVI International Botanical Congress (1999, St. Louis, USA).

Twenty years ago Professor Tamás Pócs began to examine cryptobiotic layers, that is, vegetation patches formed by cyanobacteria, algae, bryophytes and lichens in extreme habitats (loess cliffs, desert vegetation, Antarctic rocks). The importance of these layers can be seen in their representation in the record of the earliest vegetation, which played an important role in the formation of an oxidative atmosphere. He joined a research project for Mars exploration; his task was to examine whether a cryptobiotic layer could exist on the rocky surface of Mars. He lectured on the results of his research on cryptobiotic layers in 2001. His success in this new aspect of research can be seen in 48 publications about it. The year 2003 saw several publications recognizing his research in Acta Academiae Pedagogicae Agriensis in Hungarian (Fekete 2003; Orbán 2003; Varga 2003) and in Acta Botanica Hungarica in English (Orbán 2003). The latter contains the new taxa described up to 2002, taxa collected by Tamás Pócs but described by other researchers, and his publications up to 2003.

In this brief contribution it is not possible to convey the full picture of Tamás Pócs's enormous publication activity, and his passion for research, collecting and expedition organizing, pursued with youthful dynamism even during the past decade. Suffice it to say that Professor Pócs has published more than 150 works during the last ten years. An updated list of his publications can be found on the website of the Hungarian Academy of Sciences (https://www.mtmt.hu).

We wish Tamás good health, good cheer, and a lot of good results in determining his many recently collected samples.

\section{REFERENCES}

Fekete G. 2003. The years of the beginning. Tamás Pócs, the vegetation researcher. Acta Academiae Paedagogicae Agriensis Sectio Biologiae 24: 3-10.

OrBÁN S. 2003. Tamás Pócs, the tropical botanist. Academiae Paedagogicae Agriensis Sectio Biologiae 24: 11-16.

ORBÁN S. 2003. In honour of the seventy-year-old Tamás Pócs. Acta Bot. Hung. 45(3-4): 227-258.

VARGA A. 2003. Malacological pack for journey fromTamás Pócs. Academiae Paedagogicae Agriensis Sectio Biologiae 24: 19-21. 
LIST OF NEW NAMES AND COMBINATIONS BY

TAMÁS PÓCS BETWEEN 2003 AND $2012^{1}$

\section{Marchantiophyta}

Aphanolejeunea azorica (V. Allorge \& Jovet-Ast) Bernecker \& Pócs, Mem. New York Bot. Gard. 87: 109. 2003.

Archilejeunea helenae Pócs \& Gyarmati, Cryptog. Bryol. 27(1): 104. 2006.

Austrolejeunea conchophylla (Grolle) Pócs, J. Hattori Bot. Lab. 99: 186. 2006.

Austrolejeunea hamata (Grolle) Pócs, J. Hattori Bot. Lab. 99: 186. 2006.

Austrolejeunea occidentalis Pócs, J. Hattori Bot. Lab. 99: 187. 2006.

Austrolejeunea papillosa (D. Glenny) Pócs, J. Hattori Bot. Lab. 99: 186. 2006.

Austrolejeunea talynayi (S. Arnell) Pócs, J. Hattori Bot. Lab. 99: 187. 2006.

Bazzania orbanii Pócs, Acta Biol. Plant. Agriensis 1: 16. 2011.

Ceratolejeunea andringitrae Pócs, Polish Bot. J. 56(2): 144. 2011.

Ceratolejeunea saroltae Pócs, Polish Bot. J. 56(2): 149. 2011.

Cheilolejeunea streimannii Pócs \& Ninh, Acta Bot. Hung. 47(1-2): 162. 2005.

Cheilolejeunea ulugurica Malombe, Eb. Fisch. \& Pócs, Acta Biol. Plant. Agriensis 1: 24. 2011.

Cololejeunea (Spruce) Schiffn. subg. Incalejeunea Tixier ex Pócs, Acta Bryolichenol. Asiat. 4: 129. 2011.

Cololejeunea (Spruce) Schiffn. subg. Metzgeriopsis Pócs, Acta Bryolichenol. Asiat. 4: 106. 2011.

Cololejeunea altimontana Pócs, Acta Bryolichenol. Asiat. 4: 78. 2011.

Cololejeunea antillana Pócs, Polish Bot. J. 54(1): 3. 2009.

Cololejeunea arfakiana Pócs \& J. Eggers, Polish Bot. J. 51(2): 155. 2006.

Cololejeunea berneckerae Pócs, Polish Bot. J. 54(1): 4. 2009.

Cololejeunea bifalcala Pócs, Acta Bot. Hung. 54(1-2): 146. 2012.

Cololejeunea blepharophylla Pócs, Acta Bot. Hung. 54(1-2): 149. 2012.

\footnotetext{
1 Including earlier records not enumerated in Orbán (2003).
}

Cololejeunea ciliata Pócs, Acta Bryolichenol. Asiat. 4: 83. 2011.

Cololejeunea cingens (Herz.) Bernecker \& Pócs, Polish Bot. J. 54(1): 4. 2009.

Cololejeunea cornutissima (R. M. Schust.) Pócs, Polish Bot. J. 54(1): 4. 2009.

Cololejeunea costaricensis (Bernecker) Bernecker \& Pócs, Polish Bot. J. 54(1): 5. 2009.

Cololejeunea crateris Pócs, Acta Bot. Hung. 54(1-2): 153. 2012.

Cololejeunea cubensis Pócs, Polish Bot. J. 54(1): 5. 2009.

Cololejeunea erostrata (Herzog) Bernecker \& Pócs, Polish Bot. J. 54(1): 5. 2009.

Cololejeunea eustacei Pócs, J. Bryol. 29: 83. 2007.

Cololejeunea flavovittata Pócs, Acta Bryolichenol. Asiat. 4: 120. 2011.

Cololejeunea grossepapillosa (Horik.) Pócs, Polish Bot. J. 54(1): 5. 2009.

Cololejeunea iwatsukiana (Pócs) Pócs, Polish Bot. J. 54(1): 6. 2009.

Cololejeunea jovetastiana Pócs, Polish Bot. J. 54(1): 6. 2009.

Cololejeunea kolombangarae Pócs, Acta Bryolichenol. Asiat. 4: 67. 2011.

Cololejeunea kolombangarae subsp. sepikense Pócs, Acta Bryolichenol. Asiat. 4: 68. 2011.

Cololejeunea konratii Pócs, Acta Bot. Hung. 54(1-2): 157. 2012.

Cololejeunea kuciana Pócs \& Schäfer-Verwimp, Polish Bot. J. 57(1): 51. 2012.

Cololejeunea lisowskii (Pócs) Pócs, Polish Bot. J. 54(1): 6. 2009.

Cololejeunea magnifica Pócs, Acta Bryolichenol. Asiat. 4: 88. 2011.

Cololejeunea microscopica (Taylor) Schiffn. var. exigua (Evans) Pócs in Gradstein \& Ilkiu-Borges, Plants of Central French Guyana 4: 73. 2009.

Cololejeunea minuscula Pócs, Polish Bot. J. 54(1): 7. 2009.

Cololejeunea moralesiae (Bernecker) Bernecker \& Pócs, Polish Bot. J. 54(1): 7. 2009.

Cololejeunea morobensis (Pócs) Pócs, Polish Bot. J. 54(1): 7. 2009.

Cololejeunea norrisii (Pócs) Pócs, Polish Bot. J. 54(1): 7. 2009.

Cololejeunea pacifica Pócs, Acta Bot. Hung. 54(1-2): 158. 2012.

Cololejeunea panamensis G. Dauphin \& Pócs, Trop. Bryol. 27: 76. 2006. 
Cololejeunea paucifolia (Spruce) Bernecker \& Pócs, Polish Bot. J. 54(1): 8. 2009.

Cololejeunea saroltae Pócs, Acta Bot. Hung. 54(1-2): 160. 2012.

Cololejeunea schmidtii Steph. var. acutepapillosa Pócs, Acta Bot. Hung. 54(1-2): 165. 2012.

Cololejeunea sicaefolia subsp. jamaicensis (R. M. Schust.) Bernecker \& Pócs, Polish Bot. J. 54(1): 8. 2009.

Cololejeunea sicaefolia (Gottsche) Pócs \& Bernecker, Polish Bot. J. 54(1): 8. 2009.

Cololejeunea sintenisii (Steph.) Pócs, Polish Bot. J. 54(1): 8. 2009.

Cololejeunea stellaris Pócs, Acta Bryolichenol. Asiat. 4: 70. 2011.

Cololejeunea streimannii Pócs, Acta Bryolichenol. Asiat. 4: 96. 2011.

Cololejeunea streimannii subsp. solomonensis Pócs, Acta Bryolichenol. Asiat. 4: 96. 2011.

Cololejeunea subalpina Pócs, Acta Bryolichenol. Asiat. 4: 98. 2011.

Cololejeunea subsphaeroidea (R. M. Schust.) Pócs, Polish Bot. J. 54(1): 9. 2009.

Cololejeunea thiersiae (Pócs) Pócs, Polish Bot. J. 54(1): 9. 2009.

Cololejeunea touwii Pócs, Acta Bryolichenol. Asiat. 4: 101. 2011.

Cololejeunea trichomanis (Gottsche) Steph. subsp. cordiflora (Steph.) Pócs, Acta Bryolichenol. Asiat. 4: 104. 2011.

Cololejeunea tuiwawana Pócs, Acta Bot. Hung. 54(1-2): 165. 2012.

Cololejeunea verrucosa (Jovet-Ast) Pócs in Gradstein \& Ilkiu-Borges, Plants of Central French Guyana 4: 78. 2009.

Cololejeunea vuquangensis Pócs \& Ninh, Acta Bot. Hung. 47(1-2): 156. 2005

Cololejeunea winkleri (Morales \& Bernecker) Bernecker \& Pócs, Polish Bot. J. 54(1): 9. 2009.

Cololejeunea zantenorum Pócs, Acta Bryolichenol. Asiat. 4: 127. 2011.

Colura calderae Pócs, J. Bryol. 29: 84. 2007.

Colura irrorata (Spruce) Heinrichs, Y. Yu, SchäferVerwimp \& Pócs, Phytotaxa 66: 58. 2012.

Colura thomeensis Pócs, Bryologist 114(2): 363. 2011.

Colura vitiensis Pócs \& J. Eggers, Polish Bot. J. 52(2): 88. 2007.

Diplasiolejeunea eggersii Pócs, Bryologist 109(3): 408. 2006.
Diplasiolejeunea ornata Pócs \& Schäfer-Verwimp, Cryptog. Bryol. 27(4): 440. 2006.

Diplasiolejeunea ranomafanae Pócs, Cryptog. Bryol. 27(1): 444. 2006.

Drepanolejeunea inchoata (Meisn.) Steph. var. palmicola Pócs, Acta Bot. Hung. 51(3-4): 381. 2009.

Frullania vivipara Pócs, Fieldiana, Botany 47: 151. 2008.

Kurzia capillaria (Sw.) Grolle subsp. paramicola Pócs, Acta Biol. Plant. Agriensis 2: 106. 2012.

Lejeunea gradsteiniana Pócs, Acta Biol. Plant. Agriensis 1: 55. 2011.

Lejeunea kuerschneriana Pócs, Nova Hedwigia Beih. 138: 100. 2010.

Lejeunea longilobula Pócs, Nova Hedwigia Beih. 138: 112. 2010.

Lejeunea masoalae Pócs, Nova Hedwigia Beih. 138: 103. 2010.

Lejeunea vojtkoi Pócs, Nova Hedwigia Beih. 138: 107. 2010.

Myriocoleopsis vuquangensis (Pócs \& Ninh) Pócs, Trop. Bryol. 31: 124.

Otolejeunea subana Pócs Acta Academiae Paedagogicae Agriensis, Sect. Biol. 25: 50, 2004.

Phaeolejeunea amicorum (Hürl.) Pócs, Fieldiana, Botany 47: 140. 2008.

Pictolejeunea piconii Pócs, Acta Bot. Hung. 49(1-2): 110. 2007.

Plagiochila artsii Pócs, J. Hattori Bot. Lab. 100: 334. 2006.

Plagiochila hiroshiana Pócs, J. Hattori Bot. Lab. 100: 335. 2006.

Radula ornata E. A. Br. \& Pócs, Telopea 9(3): 436. 2001.

Telaranea bischleriana Pócs, Acta Bot. Hung. 48(1-2): 120. 2006.

Telaranea maorensis Pócs, Acta Bot. Hung. 48(1-2): 124. 2006.

Bryophyta

Didymodon revolutus (Cardot) Williams var. africanus Pócs, Lindbergia 32: 37. 2007.

Gymnostomum viridulum Brid. subsp. saharae Pócs, Nova Hedwigia Beih. 131: 115. 2007.

Hymenodon chenianus Pócs, Chenia 9: 27. 2007.

Gymnospermatophyta

Encephalartos kanga Pócs \& Luke, J. East African Nat. Hist. 96: 195. 2007. 
NeW taXa Dedicated to TAMÁs AND SAROlta PÓCS BETWEEN 2003 AND 2012 2

\section{Lichenes (Lichenized Fungi)}

Coenogonium pocsii (Vězda \& Farkas) Lücking, Aptroot \& Sipman, Fungal Diversity 23: 297. 2006.

Dimerella pocsii Vězda \& Farkas, Folia Geobot. Phytotax. 23(2): 193. 1988.

Fistulariella pocsii (Krog \& Swinscow) Bowler \& Rundel, Mycotaxon 6(1): 199. 1977.

Macentina pocsii Farkas \& Vězda, Folia Geobot. Phytotax. 28(3): 328. 1993.

Phyllospora pocsii Vězda, Lichenes Rariori Exsiccati 49: 2 (no. 484). 2003.

Pocsia pocsii (Farkas \& Vězda) Lücking \& Kalb, Bot. Jahrb. Syst. Pflanzenges. Pflanzengeogr.122: 47. 2000.

Porina pocsii Vězda, Folia Geobot. Phytotax. 19 (2): 188, 1984.

\section{Marchantiophyta}

Cololejeunea tamasii Schäf.-Verw., Phytotaxa 60: 9. 2012.

Herbertus pocsii N. G. Hodgetts, J. Bryol. 30(4): 249. 2008.

Lopholejeunea pocsii Gyarmati, Cryptog. Bryol. 26(4): 404. 2005.

\section{Bryophyta}

Powellia pocsii Zanten, Acta Acad. Paedagog. Agriensis, Sect. Biol. 24: 24. 2003.

Diphyscium tamasii B. C. Tan \& Tran Ninh, Acta Acad. Paedagog. Agriensis, Sect. Biol. 24: 88. 2003.

\section{Anthophyta}

Adenophora liliifolia (L.) A.DC. var. pocsii Soó, Acta Bot. Acad. Sci. Hung. 18(1-2): 174. 1973.

Asplenium pocsii Pic. Serm., Webbia 27: 432. ['1972'] 1973.

Pavetta pocsii Bridson, Kew Bull. 56(3): 581. 2001.

\section{Acarina}

Afrodacarellus pocsi Hurlbutt, Acarologia 15(4): 607. 1974.

Allogalumna pocsii Mahunka, Acta Zool. Acad. Sci. Hung. 42(2): 169. 1996.

\footnotetext{
2 Including taxa earlier not enumerated in Orbán (2003).
}

Cyllibula (Wagenaaria) pocsi Kontschán, Acta Zool. Hung. 53: 341. 2007.

Peloribates pocsi Mahunka \& Mahunka-Papp, Opusc. Zool., Budapest 42(2): 138. 2011.

Rotundabaloghia pocsiana Kontschán. Ann. Hist.-Nat. Mus. Nat. Hung. 97: 247. 2005.

Sternoppia pocsiana Mahunka, Acta Zool. Acad. Sci. Hung. 52(3): 276. 2006.

Trichouropoda pocsi Hirschmann \& Wiśniewski, Acarologie 34: 85. 1987.

Trichouropoda pocsii Kontschán, Ann. Hist.-Nat. Mus. Nat. Hung. 96: 281. 2004.

Uropoda (Phaulodinychus) pocsii Hirschmann, Acarologie 28: 113. 1981.

NEW TAXA DESCRIBED BETWEEN 2003

AND $2012^{3}$ BASED OF SPECIMENS COLLECTED BY TAMÁS AND SAROLTA PÓCS

\section{Ascomycophytina}

Bryothele mira Döbbeler \& Melnik, Nova Hedwigia 66: 337.1998.

\section{Lichenes (Lichenized fungi)}

Coenogonium tanzanicum (Vězda \& Farkas) Lücking \& Kalb, Bot. J. Linn. Soc. 139: 177.

\section{Marchantiophyta}

Herbertus spicatus N. G. Hodgetts, J. Bryol. 30(4): 244. 2008.

Lopholejeunea vojtkoana Gyarmati, Nova Hedwigia 87(3-4): 480. 2008.

\section{Acarina}

Africoribates nasalis Mahunka \& Mahunka-Papp, Opusc. Zool., Budapest 42(2): 137. 2011

Afrotrachytes longicaudatus Kontschán, Opusc. Zool., Budapest 35: 53. 2006.

Allogalumna costata Mahunka, Acta Zool. Acad. Sci. Hung. 42(2): 164. 1996.

Allogalumna insolita Mahunka, Acta Zool. Acad. Sci. Hung. 42(2): 164. 1996.

Allogalumna superporosa Mahunka, Acta Zool. Acad. Sci. Hung. 42(2): 169. 1996.

Austrocarabodes planisetus Mahunka \& MahunkaPapp, Opusc. Zool., Budapest 42(2): 130. 2011.

\footnotetext{
3 Including taxa earlier not enumerated in Orbán (2003).
} 
Beckiella costulata Mahunka, Acta Zool. Acad. Sci. Hung. 52(3): 273. 2006.

Beckiella disiuncta Mahunka, Acta Zool. Acad. Sci. Hung. 52(3): 275. 2006.

Bloszykiella africana Kontschán, Zootaxa 2525: 64. 2010.

Bloszykíella Kontschán, Zootaxa 2525: 63. 2010.

Carabodes afrominusculus Mahunka \& Mahunka-Papp, Opusc. Zool., Budapest 42(2): 132. 2011.

Comororibula Mahunka, Acta Zool. Acad. Sci. Hung. 40(3): 278. 1994.

Comororibula truncata Mahunka, Acta Zool. Acad. Sci. Hung. 40(3): 279. 1994.

Comorozetes Mahunka, International Journal of Acarology 20(1): 53. 1994.

Comorozetes atavisticus Mahunka, International Journal of Acarology 20(1): 55. 1994.

Cosmochthonius margaritatus Mahunka \& MahunkaPapp, Opusc. Zool., Budapest 42(2): 126. 2011.

Cosmozetes instans Mahunka, Acta Zool. Acad. Sci. Hung. 51(4): 294. 2005.

Damaeolus ocellatus Mahunka, Folia Entomol. Hung. 61: 23. 2000.

Dimidiogalumna comorensis Mahunka, Acta Zool. Acad. Sci. Hung. 40(3): 282. 1994.

Galumna armatifera Mahunka, Acta Zool. Acad. Sci. Hung. 42(2): 172. 1996.

Guatemalozytes atypicus Mahunka, Acta Zool. Acad. Sci. Hung. 52(3): 283. 2006.

Kakophthiracarus mwali Mahunka, Acta Zool. Acad. Sci. Hung. 40(3): 273. 1994.

Leptogalumna reducta Mahunka, Acta Zool. Acad. Sci. Hung. 42(2): 174. 1996.

Microlamellarea coetzeeae Mahunka \& Mahunka-Papp, Opusc. Zool., Budapest 42(2): 136. 2011.

Microtritia altissima Mahunka, Acta Zool. Acad. Sci. Hung. 40(3): 276. 1994.

Nothrus madagascariensis Mahunka, Folia Entomol. Hung. 61: 21. 2000.

Oplitis mauritiensis Mahunka, Ann. Hist-Nat. Mus. Nat. Hung. 97: 252. 2005.

Pergalumna fastigiata Mahunka, Acta Zool. Acad. Sci. Hung. 42(2): 177. 1996.

Persuctobelba divisa Mahunka, Acarologia 41(1-2): 277. 2000.

Persuctobelba Mahunka, Acarologia 41(1-2): 277. 2000.

Persuctobelba monster Mahunka, Acarologia 41(1-2): 281. 2000.

Pilizetes tuberculatus Mahunka, Acta Zool. Acad. Sci. Hung. 40(3): 287. 1994.
Polyaspis africanus Kontschán, Opusc. Zool., Budapest 35: 56. 2006.

Pseudotocepheus subtilis Mahunka \& Mahunka-Papp, Opusc. Zool. Budapest 42(2): 133. 2011.

Rhopalozetes bisculpturatus Mahunka, Acta Zool. Acad. Sci. Hung. 51(4): 303. 2005.

Rhopalozetes filiferus Mahunka, Acta Zool. Acad. Sci. Hung. 51(4): 305. 2005.

Rotundabaloghia benyovkyi Kontschán, Ann. Hist-Nat. Mus. Nat. Hung. 99: 174. 2007.

Rotundobaloghia kikuyu Kontschán, Folia Entomol. Hung. 65: 9. 2004.

Rotundobaloghia madagascarensis Kontschán, Ann. Hist-Nat. Mus. Nat. Hung. 99: 172. 2007.

Rotundobaloghia mahunkana Kontschán, Acta Zool. Acad. Sci. Hung. 53(4): 342. 2007.

Rotundobaloghia spatulata Kontschán, Folia Entomol. Hung. 65: 7. 2004.

Schalleria csuzdii Mahunka, Acta Zool. Acad. Sci. Hung. 51(4): 307. 2005.

Trichogalumna madagassica Mahunka, Acta Zool. Acad. Sci. Hung. 42(2): 180. 1996.

Trichouropoda caudata Mahunka, Ann. Hist-Nat. Mus. Nat. Hung. 97: 255. 2005.

Trichouropoda dimidita Hirschmann \& Wiśniewski, Acarologie 34: 83. 1987.

Trigonuropoda comorensis Kontschán, Ann. Hist-Nat. Mus. Nat. Hung. 96: 283. 2004.

Trigonuropoda gerei Kontschán, Opusc. Zool., Budapest 35: 57. 2006.

Trigonuropoda takacsi Kontschán, Opusc. Zool., Budapest 35: 59. 2006.

Trigonuropoda ulugurensis Hiramatsu, Acarologie 28: 103. 1981.

Tuberemaeus puruczkyi Mahunka \& Mahunka-Papp, Opusc. Zool., Budapest 42(2): 143. 2011.

Uropoda (Phaulodinychus) ancorae Hirschmann, Acarologie 28: 113. 1981.

Uropoda (Phaulodinychus) ancoraesimilis Hirschmann, Acarologie 28: 112. 1981.

Uropoda (Phaulodinychus) solarissima Hirschmann, Acarologie 28: 112. 1981.

Urubambates xerophyilus Mahunka, Opusc. Zool., Budapest 36: 71. 2007.

\section{Mollusca}

Hydrocena tanzaniensis Verdcourt, Ann. Hist-Nat. Mus. Nat. Hung. 96: 300. 2004.

Edentuina parensis Verdcourt, Ann. Hist-Nat. Mus. Nat. Hung. 96: 303. 2004. 


\section{BIBLIOGRAPHY OF TAMÁS PÓCS}

\section{4}

KÁRolyi A. \& Pócs T. 1954. Adatok Délnyugat-Dunántúl növényföldrajzához. (Zur Pflanzengeographie SüdwestTransdanubiens). Botanikai Közlemények 45: 257-267.

Pócs T. 1954. A rákoskeresztúri „Akadémiai erdő” vegetációja. (Die Vegetation des „Akademischen Waldes” in Rákoskeresztúr). Botanikai Közlemények 45: 283-294.

\section{7}

KÁROlYI A. \& Pócs T. 1957. Újabb adatok Délnyugat-Dunántúl növényföldrajzához. (Neuere Angaben zu der Flora von Südwest-Transdanubien). Annales Historico-Naturales Musei Nationalis Hungarici - A Magyar Természettudományi Múzeum Évkönyve 8: 197-204.

Pócs T. \& Simon T. 1957. Aubrietia croatica Sch., Nym. et Ky., neu für die Flora der Karpaten und Rumäniens. Acta Botanica Academiae Scientiarum Hungaricae 3: 31-36.

Pócs T., Borhidi A., JuhÁsz-Nagy P., SimOn T. \& VidA G. 1957. Contributions á la flore des Carpathes Orientaux et Méridionaux. Annales Historico-Naturales Musei Nationalis Hungarici-A Magyar Természettudományi Múzeum Évkönyve 8: 206-218.

\section{8}

Pócs T. 1958. Data to the knowledge and Hungarian distribution of the taxonomical group Polygala nicaeensis [Adatok a Polygala nicaeensis Risso alakkörének ismeretéhez és magyarországi előfordulásához] . MTA Biológiai Csoportjának Közleményei 2: 235-247.

Pócs T. 1958. Beiträge zur Moosflora Ungarns und der Ost- und Südkarpaten. Annales Historico-Naturales Musei Nationalis Hungarici - A Magyar Természettudományi Múzeum Évkönyve 9: 107-119.

Pócs T. 1958. Phytogeographical conclusions from vegetation maps made in West-Transdanubia. In: R. MAUCHA (ed.), Proceedings of the Second Meeting of the Hungarian Biological Society. Szeged, Hungary, 19-21 May 1958, p. 15. Hungarian Biological Society, Budapest

PÓcs T., DOMOKOSNÉ NAGY E., PÓCSNÉ GElENCSÉR I. \& VIDA G. 1958. Vegetationsstudien im Örség: ungarisches Ostalpenvorland. Akadémiai Kiadó, Budapest. 124 pp.

\section{9}

KÁRpÁtI Z. \& Pócs T. 1959. The biogeographical parts of Western Hungary [Dunántúl növényföldrajzi tagozódása]. In: Proceedings of 3rd Biological Meeting A III. Biológiai Vándorgyülés elöadásainak ismertetése, Budapest, Hungary, 05-07.05.1959, p. 27. Hungarian Biological Society, Budapest
1960

AgÓCSY P. \& Pócs T. 1960. Data to the mollusk fauna of Hungary. Annales Historico-Naturales Musei Nationalis Hungarici - A Magyar Természettudományi Múzeum Évkönyve 52: 438-445.

Pócs T. 1960. Die Verbreitung von Leptodon smithii (Dicks.) Mohr. und die Verhältnisse seiner Vorkommen. Annales Historico-Naturales Musei Nationalis Hungarici - A Magyar Természettudományi Múzeum Évkönyve 52: 169-176.

Pócs T. 1960. Die zonalen Waldgesellschaften Südwestungarns. Acta Botanica Academiae Scientiarum Hungaricae 6: $75-105$.

Pócs T. 1960. Einige Daten zur Moosflora Jugoslawiens. Annales Historico-Naturales Musei Nationalis Hungarici - A Magyar Természettudományi Múzeum Évkönyve 52: 163-168.

Pócs T. 1960. Zonalne zespoły leśne połudnowo-zachodnich Wegier. [The zonal forest communities of southwest Hungary]. Wiadomości Botaniczne 4(3-4): 245-257.

\section{1}

Agócsy P. \& Pócs T. 1961. Alopia soósiana n. sp. (Mollusca, Gastropoda). Annales Historico-Naturales Musei Nationalis Hungarici - A Magyar Természettudományi Múzeum Évkönyve 53: 533-536.

KÁrolyi A. \& Pócs T. 1961. The occurrence of Helicigona (Campylea) illyrica Stabile in Hungary (Mollusca, Gastropoda). Annales Historico-Naturales Musei Nationalis Hungarici - A Magyar Természettudományi Múzeum Évkönyve 53: 531-532.

Pócs T. 1961. Die zonalen Waldgesellschaften des Ungarischen Alpenvorlandes. In: Mitteilungen der Ostalpin-Dinarischen pflanzensoziologischen Arbeitsgemeinschaft 1 . Padova, Italy, 1961, pp. 37-40. Padova, Italy. http://www. odin.sbg.ac.at/index.php?option=com_eventtableedit\&vie $\mathrm{w}=$ default\&Itemid $=62$

Pócs T. 1961. Flore du massif du Parîng (Carpathes méridionaux en Roumanie, I.). Fragmenta Botanica 1: 49-128.

Pócs T. 1961. The calculation of the quantitative grade of efficacy of collecting and extracting methods of materials used in zoocoenology. Annales Historico-Naturales Musei Nationalis Hungarici - A Magyar Természettudományi Múzeum Évkönyve 53: 259-265.

Pócs T. 1961. Mapping the vegetation of vendvidék: II. Plant associations of Vendvidék. [Vendvidék vegetációjának térképezése: II.a. Vendvidék növénytársulásai]. Botanikai Közlemények 49: 134.

\section{2}

CSAPody I., HorÁnSZKY A., PÓCS T., SimOn T., SzOdFridT I. \& TALLÓs P. 1962. Ecological characteristics of Hungarian herbs. [Lágyszárú növényeink ökológiai viszonyai]. In: 
A. MAJER (ed.), Manual of forest and habitat typology (Erdö és termöhelytipológiai utmutató), pp. 165-175. Országos Erdészeti Főigazgatóság, Budapest.

Pócs T. 1962. Flore du massif du Parîng (Carpathes méridionaux en Roumanie, II). Fragmenta Botanica 2: 73-130.

PócS T. 1962. Szakonyfalu környékének vegetációtérképe. (,Vegetation map of the surroundings of Szakonyfalu”). Az Egri Tanárképzö Főiskola Tudományos Közleményei 8: $449-478$.

\section{3}

CSAPody I., HorÁnszKy A., Pócs T., SimOn T., SZODFRIDT I. \& TALlós P. 1963. Die Ökologischen Artengruppen der Walder Ungarns. Acta Agronomica Hungarica 12(3-4): 209-232.

Pócs T. 1963. Adatok a Déli-Kárpátok növénytakarójának ismeretéhez. (Daten zu den Kenntnissen über die Pflanzendecke der Süd-Karpaten). Az Egri Tanárképzö Föiskola Tudományos Közleményei 9: 229-247.

Pócs T. 1963. Egy északi növényfaj, a Lysimachia thyrsiflora hazánkban. (Vorkommen der Lysimachia thyrsiflora in Ungarn). Az Egri Tanárképzö Föiskola Tudományos Közleményei 9: 249-251.

Pócs T. 1963. The floristic elements of the Democratic Republic of Vietnam. Acta Botanica Academiae Scientiarum Hungaricae Supplementum 5: 28.

\section{5}

KÁROlYI A. \& Pócs T. 1965. Újabb adatok Délnyugat-Dunántúl flórájához III. (Neuere Angaben zur Flora von Südwest-Ungarn III). Savaria A Vas Megyei Múzeumok Értesitöje 2: 43-54.

KUC M., VAJDA L. \& Pócs T. 1965. Két bulgáriai tanulmányút mohagyüjtéseinek eredményei. - Mosses collected during two study-tours in Bulgaria 1959 and 1962. Botanikai Közlemények 52: 7-18.

Pócs T. 1965. Analyse aire-géographique et ecologique de la flore du Vietnam Nord. Az Egri Tanárképzö Föiskola Tudományos Közleményei 3: 395-452.

Pócs T. 1965. Prodrome de la bryoflore du Vietnam. $A z$ Egri Tanárképző Főiskola Tudományos Közleményei 3: 453-495.

Pócs T., KHOI N. D. \& TiEP N. A. 1965. Melastomacées nouvelles du Viet-Nam Nord. Annales Historico-Naturales Musei Nationalis Hungarici - A Magyar Természettudományi Múzeum Évkönyve 57: 165-168.

\section{6}

Pócs T. 1966. Bryoxiphium norvegicum subsp. japonicum (Berggr.) Löve et Löve in the Indonesian Archipelago. Miscellanea Bryologica et Lichenologica 4: 35-37.
Pócs T. 1966. Statisztikus matematikai módszer növénytársulások elhatárolására. (,Statistacal method for the delimitation of plant communities"). Az Egri Tanárképzö Föiskola Tudományos Közleményei 4: 442-454.

Pócs T. 1966. The coenological features of Hungarian Pine forests. [A magyarországi tülevelü erdők cönológiai és ökológia viszonyai: Kandidátusi értekezés] 7 pp. (Candidate).

\section{7}

KHOI N. D. \& Pócs T. 1967. Données complémentaires a la connaissance de la flore vasculaire du Nord Vietnam, I. Az Egri Tanárképző Főiskola Tudományos Közleményei 5: 405-418.

Pócs T. 1967. A - Carte phyto-écologique et carte de l'occupation des terres. B - Cartes factorielles de la zone de „1000 hectares” de Sologne. Geodézia és Kartográfia 1: 5 .

Pócs T. 1967. Aconito-Fagetum et Melitti-Fagetum subcarpaticum. In: B. ZÓlYOMI (ed.), Guide der Exkursionen des Internationalen Geobotanischen Symposiums, Eger, Hungary, 5-10.06.1967, pp. 25-28. Magyar Tudományos Akadémia, Budapest.

Pócs T. 1967. Carte phyto-écologique et carte de l'occupation des terres, Cartes factorielles de la zone de „,1000 hectares” de Sologne. Geodézia és Kartográfia 19(1): 73-74.

Pócs T. 1967. Contribution a la Bryoflore du Nord Vietnam. Revue Bryologique et Lichenologique 34: 799-806.

Pócs T. 1967. Dictionary of Hungarian plant names [Csapody Vera - Priszter Szaniszló:Magyar növénynevek szótára]. Mezögazdasági Kiadó, Budapest, 1966. Botanikai Közlemények 54: 203-204.

Pócs T. 1967. Néhány adat hazánk mohaflórájához. („A few records to the Hungarian bryoflora"). Az Egri Tanárképzö Főiskola Tudományos Közleményei 5: 419-421.

PócS T. \& TIXIER P. 1967. On the ciliferous Syrrhopodon species in Asia. Annales Historico-Naturales Musei Nationalis Hungarici-A Magyar Természettudományi Múzeum Évkönyve 59: 125-134.

Pócs T., Tixier P. \& JoveT-Ast S. 1967. Adatok Észak-Vietnam mohaflórájához. II. - Seconde contribution a la Bryoflore du Nord Vietnam. Botanikai Közlemények 54: 27-38.

Pócs T., Borhidi A., JuhÁsz-Nagy P., Simon T., Skoflek I. \& VIDA G. 1967. Contribution á la flore des Carpathes orientaux et méridionaux. Annales Historico-Naturales Musei Nationalis Hungarici - A Magyar Természettudományi Múzeum Évkönyve 8: 205-217.

\section{8}

HortobÁgyi T., Pócs T. \& Simon T. 1968. The development of Plants [A növényvilág kialakulása]. In: T. HORTOBÁGYI 
(ed.), Növénytan. 2. Növényrendszertan és növényföldrajz, pp. 469-485. Tankönyvkiadó, Budapest.

KÁRolyi A. \& Pócs T. 1968. Délnyugat Dunántúl flórája I. (Flora regionis Hungariae Meridio-occidentalis I). Az Egri Tanárképzö Főiskola Tudományos Közleményei 6: 329-390.

Pócs T. 1968. Flore du massif du Parîng (Carpathes méridionaux en Roumanie, III). Fragmenta Botanica 5: 70-100.

PÓcs T. 1968. XIII. Törzs: Mohák - Bryophyta. In: T. HoRTOBÁGYI (ed.), Növénytan. 2. Növényrendszertan és növényföldrajz, pp. 190-211. Tankönyvkiadó, Budapest.

Pócs T. 1968. Phytogeography and ecology (Növényföldrajz és ökológia). In: T. HorTobÁGYI (ed.), Növénytan. 2. Növényrendszertan és növényföldrajz, pp. 489-649.Tankönyvkiadó, Budapest.

Pócs T. 1968. The genus Porella in Vietnam. Journal of the Hattori Botanical Laboratory 31: 65-93.

Pócs T. 1968. Troisième contribution à la bryoflore du Nord Vietnam. Récoltes polonaises aux environs de Sapa. Fragmenta Floristica et Geobotanica 14: 495-504.

\section{9}

KÁROLYI A. \& Pócs T. 1969. Délnyugat Dunántúl flórája II. (Flora regionis Hungariae Meridio-occidentalis II). $A z$ Egri Tanárképzö Főiskola Tudományos Közleményei 7: 329-377.

Pócs T. 1969. A short survey of the Bazzania of North VietNam. Journal of the Hattori Botanical Laboratory 32: 79-94+204.

Soó R., Borhidi A., CSAPODY I., KovÁcs M. \& Pócs T. 1969. Die Wälder und Wiesen West- und Süd-transdanubiens und ihre Böden. Acta Botanica Academiae Scientiarum Hungaricae 15(1-2): 137-165.

1970

KÁrolyi A., Pócs T. \& BALOGH M. 1970. Délnyugat-Dunántúl flórája III. (Flora regionis Hungariae meridio-occidentalis III). Az Egri Tanárképzö Föiskola Tudományos Közleményei 8: 469-495.

Pócs T. 1970. Adatok Észak-Vietnam mohaflórájához. V. (Fifth contribution to the bryoflora of North Vietnam). Botanikai Közlemények 56: 139-147.

\section{1}

KÁrolyi A., Pócs T. \& BAlogh M. 1971. Délnyugat-Dunántúl flórája IV. (Flora regionis Hungariae meridio-occidentalis IV). Az Egri Tanárképzö Föiskola Tudományos Közleményei 9: 387-409.

Pócs T. 1971. Studies on the mountain bryoflora of the Ha-Giang province (Democratic Republic of Vietnam): Hepaticae. Botanicheskiy Zhurnal 56: 670-677.
Pócs T. 1971. Studies on the mountain bryoflora of the HaGiang province (Democratic Republic of Vietnam): Musci. Botanicheskiy Zhurnal 56: 845-853.

\section{2}

KÁRolyi A., Pócs T. \& BALOGH M. 1972. Délnyugat-Dunántúl flórája V. (Flora regionis Hungariae meridio- occidentalis V). Az Egri Tanárképzö Föiskola Tudományos Közleményei 10: 373-400.

\section{3}

Pócs T. 1973. Sooia ulugurica genus et species nova Acanthacearum. Acta Botanica Academiae Scientiarum Hungaricae 19: 461-466.

\section{4}

Bizot M. \& Pócs T. 1974. East African bryophytes, I. $A z$ Egri Tanárképzö Föiskola Tudományos Közleményei 12: 383-449.

Bizot M., Pierrot R. B. \& Pócs T. 1974. Trois genres nouveaux de Muscinées. Revue Bryologique et Lichenologique 40: $25-31$.

KÁrolyi A., Pócs T. \& BALOGH M. 1974. Délnyugat-Dunántúl flórája VI. (Flora regionis Hungariae meridio-occidentalis VI). Az Egri Tanárképzö Föiskola Tudományos Közleményei 12: 451-463.

Pócs T. 1974. Bioclimatic studies in the Uluguru Mountains (Tanzania, East Africa). I. Acta Botanica Academiae Scientiarum Hungaricae 20: 115-135.

Pócs T. 1974. Bryological research in Hungary. Taxon 23: 882-883.

Pócs T. 1974. Epiphyllous liverworts from Zambia. Bulletin de l'Académie Polonaise des Sciences, Série des Sciences Biologiques 22: 851-853.

\section{5}

Bakalár I., Orbán S., PÓcs T., Suba J. \& VAJdA L. 1975. Adatok a Tarnavidék mohaflórájához. (Data to the moss flora of the Tarna country). Studia Botanica Hungarica 10: $111-114$.

Pócs T. 1975. Affinities between the bryoflora of East Africa and Madagascar. Boissiera 24a: 125-128.

Pócs T. 1975. Bottom Alps and Kemeneshát (Alpokalja és Kemeneshát). In: L. ÁDÁM \& S. MAROSI (eds), A Kisalföld és a Nyugatmagyarországi peremvidék (Magyarország tájföldrajza 3), pp. 430-431. Akadémiai Kiadó, Budapest.

Pócs T. 1975. Correlations between the tropical African and Asian bryofloras. In: Abstracts of the papers presented at the XII. International Botanical Congress, Leningrád, Soviet Union, 3-10 July 1975, p. 86. University Publisher, Leningrad. 
Pócs T. 1975. Natural vegetation [Természetes növénytakaró]. L. ÁDÁM \& S. MAROSI (eds), A Kisalföld és a Nyugatmagyarországi peremvidék (Magyarország tájföldrajza 3), pp. 324-325. Akadémiai Kiadó, Budapest.

Pócs T. 1975. Sopron-Vas Plains [Sopron-Vasi sikság]. In: L. ÁDÁM \& S. MAROSI (eds), A Kisalföld és a Nyugatmagyarországi peremvidék (Magyarország tájföldrajza 3), pp. 379-384. Akadémiai Kiadó, Budapest.

Pócs T. 1975. Zala Hills Zalai-dombság. L. ÁDÁM \& S. MAROSI (eds), A Kisalföld és a Nyugatmagyarországi peremvidék (Magyarország tájföldrajza 3), pp. 469-471. Akadémiai Kiadó, Budapest.

\section{6}

BAKAlár S., Orbán S., Pócs T., SubA J. \& VAJdA L. 1976. Data to the Bryophyte Flora of Tarna region [Adatok a Tarnavidék mohaflórájához]. Studia Botanica Hungarica 10: 111-114.

BAlogh M., KÁROlYi A. \& Pócs T. 1976. Délnyugat-Dunántúl flórája VII. Az Egri Tanárképző Főiskola Tudományos Közleményei 13: 395-415.

ORBÁN S. \& PóCS T. 1976. Rhodobryum ontariense (Kindb.) Kindb. in Central Europe. Acta Botanica Academiae Scientiarum Hungaricae 22: 437-448.

Pócs T. 1976. Botanical collections made in East Africa during 1969-1973. Boissiera 24: 605.

Pócs T. 1976. New or little known epiphyllous liverworts I. Cololejeunea from tropical Africa. Acta Botanica Academiae Scientiarum Hungaricae 22: 353-375.

Pócs T. 1976. The role of the epiphytic vegetation in the water balance and humus production of the rain forests of Uluguru Mountains, East Africa. Boissiera 24b: 499-503.

Pócs T. 1976. Vegetation mapping in the Uluguru mountains (Tanzania, East Africa). Boissiera 24b: 477-498+1 map.

Pócs T. 1976. Correlations between the tropical African and Asian bryofloras. I. Journal of the Hattori Botanical Laboratory 41: 95-106.

\section{7}

Bizot M., DuRY M. N. \& Pócs T. 1977. East African Bryophytes, II. Collections made by L. Ryvarden in Malawi, SE Africa. Acta Botanica Academiae Scientiarum Hungaricae 22: 1-8.

Pócs T. 1977. Report ont he 12th International botanical Congress, 5th Section [Beszámoló a XII. Nemzetközi Botanikai Kongresszusról. 5. szekció]. Botanikai Közlemények 63: 183-184.

Pócs T. 1977. Bioclimatic studies in the Uluguru Mountains (Tanzania, East Africa) II. Correlations between orography, climate and vegetation. Acta Botanica Academiae Scientiarum Hungaricae 22: 163-183.
Pócs T. 1977. Type catalogue of the Bryophyte Herbarium of Ho Si Minh Teachers' College, Eger, Hungary. Folia Historico-Naturalia Musei Matraensis 4: 15-36.

Pócs T. 1977. Complex vegetation studies in East Africa (Tanzania, Uluguru mountains) Doctorate thesis Komplex vegetációtanulmányok Kelet-Afrikában (Tanzánia, Uluguru hegység): Doktori értekezés tézisei. 14 pp.

\section{8}

Bizot M., FriIs I., LEWINSKY J. \& PÓCs T. 1978. East African bryophytes, IV. Danish collections. Lindbergia 4(3-4): 259-284.

Pócs T. 1978. Bryological workshop in Hungary, June 1978. Taxon 27: 433.

Pócs T. 1978. Changes in Hungarian bryology. Taxon 27: 434-435.

Pócs T. 1978. Epiphyllous communities and their distribution in East Africa. Bryophytorum Bibliotheca 13: 681-714.

Pócs T. \& ReYes D. M. 1978. Projects: Liverwort Flora of Cuba (Hepáticas de Cuba). Taxon 27: 436.

\section{9}

Bizot M. \& Pócs T. 1979. East African bryophytes, III. Acta Botanica Academiae Scientiarum Hungaricae 25(3-4): 223-261.

Bizot M., Pócs T. \& SHARP A. J. 1979. Results of a bryogeographical expedition to East Africa in 1968, II. Journal of the Hattori Botanical Laboratory 45: 145-165.

Pócs T. 1979. Bryotaxonomical and chorological research in Hungary: Proceedings, Conferentia Bryologorum, 5-8. Junii 1978 in Eger. Abstracta Botanica 5(Suppl. 3): 43-45.

VÁŇA J., Pócs T. \& De Sloover J.-L. 1979. Hépatiques d'Afrique tropicale. Lejeunia 98: 1-23.

\section{0}

Pócs T. 1980. New or little known epiphyllous liverworts, II. Three new Cololejeunea from East Africa. Journal of the Hattori Botanical Laboratory 48: 305-320.

Pócs T. 1980. The epiphytic biomass and its effect on the water-balance of two rain-forest types in the Uluguru Mountains (Tanzania, East Africa). Acta Botanica Academiae Scientiarum Hungaricae 26(1-2): 143-167.

\section{1}

KIS G. \& PócS T. 1981. Light-microscope studies on the oil bodies of Cuban liverworts. 1. Acta Botanica Academiae Scientiarum Hungaricae 27(3-4): 403-419.

NinH T. \& Pócs T. 1981. Noguchiodendron, a new genus of the moss family Neckeraceae. Acta Botanica Academiae Scientiarum Hungaricae 27(1-2): 161-168. 
PócS T. 1981. Report of a „Mini-Symposium” on African Bryology held in Poznań, June 1980. Bryological Times 7: $3-4$.

ZANTEN B. O. VAN \& PÓCS T. 1981. Distribution and dispersal of bryophytes. Advances in Bryology. Vaduz 1: $479-562$.

\section{2}

Bizot M. \& Pócs T. 1982. East African bryophytes, V. Acta Botanica Academiae Scientiarum Hungaricae 28(1-2): 15-64.

Borhidi A. \& Pócs T. 1982. Basic research for measuring ecological potencial in dveloping countries [Alapozó kutatások az ökológiai potenciál felméréséhez fejlődő trópusi országokban]. MTA Biológiai Tudományok Osztályának Közleményei 25(3-4): 437-447.

OChYRA R. \& PÓcs T. 1982. East African bryophytes. VI. Polish collections. Acta Botanica Academiae Scientiarum Hungaricae 28(3-4): 361-389.

Pócs T. 1982. An epiphyllous liverwort community from the Caucasus Mountains. Bryologische Beitrage 1: 13-22.

Pócs T. 1982. Hepaticological exploration in Subsaharan Africa. Beihefte zur Nova Hedwigia 71: 495-500.

Pócs T. 1982. The projected Hepatic Flora of Cuba. Beihefte zur Nova Hedwigia 71: 523-524.

Pócs T. 1982. The forest flora and vegetation of the old crystalline mountains of Tanzania and their importance for soil and water conservation. In: Proceedings of Seminar/ Workshop on Forest Conservation in Tanzania, Tanga, Tanzania, 16-18 February 1982, p. 5. UTAFITI, Dar esSalaam.

Pócs T. 1982. Vegetation mapping in relation to land use of forest environment in the Uluguru Mountains. In: Seminar/ Workshop on Forest Conservation in Tanzania, Tanga, Tanzania, 16-18 February 1982, p. 12. UTAFITI, Dar es-Salaam.

Pócs T. 1982. Tropical forest bryophytes. In: A. J. E. SMITH (ed.), Bryophyte ecology, pp. 59-104. Chapman and Hall, London.

\section{3}

AKÉ-Assi L. \& Pócs T. 1983. Hépatiques de Côte d'Ivoire, I. Cryptogamie - Bryologie Lichenologie 4: 65-70.

CsiK M., KIs G., Pócs T. \& BorzsonYi M. 1983. Electronmicroscope study of oil body formation in adult liverwort cells. Mikroskopie 40(3-4): 106.

Gradstein S. R., PÓCs T. \& VÁŇA J. 1983. Disjunct hepaticae in tropical America and Africa. Acta Botanica Hungarica 29(1-4): 127-171.

Pócs T. 1983. Javorka Sandor as reflected in the remembrances of a pupil. Botanikai Közlemények 70(1-2): 1-3.
Pócs T. 1983. Present knowledge on Aphanolejeunea Evans. In: The World Conference of Bryology, Tokyo, Japan, 22-28 May 1983, p. 24. Tokyo.

\section{4}

Huneck S., Connolly J. D., HaRrison L. J., Joseph R. S. I. \& Pócs T. 1984. 1-(3,4-dihydroxy-5-methoxyphenil)-3-methylbut-2-ene from the liverwort Plagiochila rutilans. Phytochemistry 23: 2396-2397.

Pócs T. 1984. New or little known epiphyllous liverworts, III. The genus Aphanolejeunea Evans in tropical Africa. Cryptogamie - Bryologie Lichenologie 5: 239-267.

Pócs T. 1984. Synopsis of the African Lepidozioideae K.Müll. In: J. VÁŇA (ed.), Proceedings of the Third Meeting of the Bryologists from Central and East Europe, Praha, Czech Republic, 14-18 June 1982, pp. 107-119. Universita Karlova, Praha.

Pócs T. 1984. Present knowledge on Aphanolejeunea Evans. Journal of the Hattori Botanical Laboratory 55: 307-313.

\section{5}

Bizot M., Pócs T. \& Sharp A. J. 1985. Results of a bryogeographical expedition to East Africa in 1968. III. Bryologist 88(2): 135-142.

BorHIDI A. \& PÓCs T. 1985. Effects of serpentine on the distribution of cryptogams in Cuba. In: T. Pócs T. \& T. SIMON (eds), Abstracts of the IAB Conference of Bryoecology, Budapest, Hungary, 5-10 August 1985, p. 10. Academic Publisher, Budapest.

MeEnKs J. D. L. \& Pócs T. 1985. East African bryophytes IX. Aneuraceae. Abstracta Botanica 9: 79-98.

OChYRA R. \& PÓcs T. 1985. East African bryophytes, VIII. The Musci of the Usambara Rain Forest Expedition, 1982. Acta Botanica Academiae Scientiarum Hungaricae 31: 135-146.

OChYRA R. \& Pócs T. 1985. East African bryophytes, X. K.Norikoshi's collectioon from Mahale Mountains National Park, Western Tanzania. Hikobia 9: 387-394.

PÁTKAI T., Pócs T. \& KIS G. 1985. SEM-EDX studies on mosses from polluted environments. In: Electron Microscopy held together with XIIIth Hungarian National Conference on Eelctron microscopy, Balatonaliga, Hungary, 25-27 April 1985, p. 111.

Pócs T. 1985. East African bryophytes, VII. The Hepaticae of the Usambara Rain Forest Project Expedition, 1982. Acta Botanica Hungarica 31(1-4): 113-133.

Pócs T. 1985. Lepidozia. In: P. GeISSLER \& H. BISCHLER (eds), Index Hepaticarum 10: Lembidium to Mytilopsis, pp. 17-49. J. Cramer Verlag, Vaduz.

Pócs T. 1985. Competition and survival strategies in foliicolous communities. In: T. Pócs T. \& T. SiMON (eds), Abstracts of the IAB Conference of Bryoecology, Budapest, 
Hungary, 05-10 August 1985, p. 32. Academical Publisher, Budapest.

Pócs T. \& SIMON T. (eds) 1985. Abstracts of the IAB Conference of Bryoecology, Budapest, Hungary, 05-10 August 1985. Budapest.

\section{6}

OCHYRA R. \& PÓcs T. 1986. East African bryophytes, XI. Dr. L. Péntek's collection from Mozambique. Abstracta Botanica 2: 63-86.

\section{7}

Jones E. W. \& Pócs T. 1987. African Hepatics. XXXVI. Three new species of Colura. Journal of Bryology 14: 495-501.

MahunKa S., Pócs T. \& Zicsi A. 1987. A report on the soilzoological collecting trip in Tanzania, 1987. Folia Entomologica Hungarica 48: 255-263.

Pócs T. 1987. Lepidoziaceae. In: W. FREY (ed.), Moosflora und -vegetation in Regenwäldern NO-Perus: Ergebnisse der Bryotrop-Expedition nach Peru 1982, p. 67. J. Cramer Verlag, Berlin 1987.

Pócs T., Simon T., Tuba Z. \& Podani J. (eds) 1987. Proceedings of the IAB Conference of Bryoecology, Budapest-Vácrátót, Hungary, 5-10 August, 1985. (Symposia Biologica Hungarica 35, Part A and B) Akadémiai Kiadó, Budapest.

Pócs T. 1987. Changes in the biomass and productivity of bryophytes in East African rain forests. In: XIV International Botanical Congress, Berlin, Germany, 24 July 1 August 1987, p. 264. Berlin.

\section{8}

Pócs T. 1988. Biogeography of the Cuban bryophyte flora. Taxon 37(3): 615-621.

Pócs T. 1988. Plagiochila rudolfii sp. nov., from Tanzania, East Africa. Beihefte zur Nova Hedwigia 90: 223-233.

Pócs T. 1988. The importance of catchment forest to Tanzania. Professorial inaugural lecture. Sokoine University of Agriculture, Tanzania, $20 \mathrm{pp}$.

Pócs T. 1988. Check-list. Bryophyta of the Usambara Mountains. In: S. T. IVERSEN, The SAREC supported Integrated Usambara Rain Forest Project Tanzania: Report for the period 1983-1987, Tanzania, p. 14. Uppsala University Press, Uppsala.

\section{9}

Borhidi A., FARKAS E. \& PóCs T. 1989. Trópusi projektek taxonómiai eredményei. A biodiverzitás tanulmányozásának módszerei és eredményei. In: G. VIDA, A. BORHIDI, L. PAPP \& A. DEMETER (eds), A biodiverzitás tanulmányozásának módszerei és eredményei. MTA és a MBT közös tudományos rendezvénye: Poszter kivonatok, Budapest, Hungary, 27 April 1989, p. 4. Budapest.

FARKAS E. \& PÓCS T. 1989. Foliicolous lichen-mimicry of a rainforest treefrog? Acta Botanica Hungarica 35(1-2): 73-76.

Gradstein S. R. \& Pócs T. 1989. Bryophytes. In: H. LIETH \& M. J. A. WERGER (eds), Tropical rain forest ecosystems. Biogeographical and ecological studies, pp. 311-325. Elsevier, Amsterdam - New York.

Pócs T. 1989. A preliminary study of the undergrowth of primary and secondary submontane rainforests in the East Usambara Mountains, with notes on epiphytes. In: R. BENSTED-SMITH \& A. C. HAMILTON (eds), Forest conservation in the East Usambara mountains Tanzania, pp. 301-306. IUCN, Cambridge.

Pócs T. 1989. Macrolichens of East Africa. By T. D. V. Swinscow and Hildur Krog: London: British Museum (Natural History). June 1988. Lichenologist 21: 190-191.

SPENCE J. R. \& PÓCS T. 1989. Distribution patterns in the Afroalpine moss flora of East Africa. In: W. C. MAHANEY (ed.), Quaternary and Environmental Research on East African Mountains, pp. 291-307. Balkema Publishers, Rotterdam.

\section{0}

Pócs T. 1990. Correlations between tropical African and Asian bryofloras, II. In: T. KOPONEN \& J. MANTTARI (eds), Congress of East Asiatic Bryology, Helsinki, Finland, 12-19 August 1990, p. 8. Helsinki.

Pócs T. 1990. The exploration of the East African bryoflora. Tropical Bryology 2: 177-191.

Pócs T. 1990. The gene pool values and their conservation in the natural forests. Sokoine University of Agriculture. Faculty of Forestry: Record 43: 16-32.

Pócs T. 1990. Excursion to the east Usambara Mountains, near Amani. In: A. NuRMI (ed.), Tansania 1988. Helsingin yliopiston kasvitieteen laitoksen opinto- ja tutkimusmatka Tansaniaan joulukuussa 1988. (Vegetation and ecology of montane and rain forest: field excursion of the Department of Botany in Tanzania in December 1988). Publications from the Department of Botany, University of Helsinki 16: $97-101$.

Pócs T. 1990. Excursion to the Mount Meru, near Olmotonyi. In: A. NURMI (ed.), Tansania 1988. Helsingin yliopiston kasvitieteen laitoksen opinto- ja tutkimusmatka Tansaniaan joulukuussa 1988. (Vegetation and ecology of montane and rain forest: field excursion of the Department of Botany in Tanzania in December 1988). Publications from the Department of Botany, University of Helsinki 16: 111-116.

Pócs T. 1990. Arid vegetation between Mkomazi and same at the southwestern foot of the Pare Mountains. In: A. NURMI (ed.), Tansania 1988. Helsingin yliopiston kasvitieteen 
laitoksen opinto-ja tutkimusmatka Tansaniaan joulukuussa 1988. (Vegetation and ecology of montane and rain forest: field excursion of the Department of Botany in Tanzania in December 1988). Publications from the Department of Botany, University of Helsinki 16: 116-117.

Pócs T. 1990. Excursion to Kimboza Forest Reserve at the Eastern foothills of Uluguru Mountains. In: A. NURMI (ed.), Tansania 1988. Helsingin yliopiston kasvitieteen laitoksen opinto- ja tutkimusmatka Tansaniaan joulukuussa 1988. (Vegetation and ecology of montane and rain forest: field excursion of the Department of Botany in Tanzania in December 1988). Publications from the Department of Botany, University of Helsinki 16: $117-119$.

\section{1}

BJÖRNDALEN J. E. \& PÓCS T. 1991. Application of vegetation maps for monitoring rain forest catchments in Tanzania. In: J. B. FALIŃSKI (ed.), Vegetation processes as subject of geobotanical map. Proceedings of XXXIII Symposium of IAVS, Warsaw, April 8-12. 1990. Phytocoenosis 3 (N.S.) Supplementum Cartographiae Geobotanicae 2: 87-94.

Magill R. E. \& Pócs T. 1991. A guide for contributors to Bryologia Africana, a Bryophyte Flora of Tropical Africa. Missouri Botanical Garden, St. Louis.

Pócs T. 1991. Bryologia Africana news. Bryological Times 62-63: 8.

Pócs T. 1991. Geography and ecology of Usambara's bryophytes. In: I. Hedberg \& E. Persson (eds), Research for Conservation of Tanzanian Catchment Forests: Proceedings from a workshop held in Morogoro, Tanzania, March 13-17, 1989, Morogoro, Tanzania, 13-17 March 1989, pp. 71-85. Uppsala University Press, Sweden.

PÓcs T. \& O’SHEA B. J. 1991. Quick reference list of basic literature to identify tropical African bryophytes. Tropical Bryology 4: 69-84.

Pócs T. 1991. The altitudinal distribution of Kilimanjaro bryophytes. In: J. H. SEYANI (ed.), The XIIIth AETFAT Congress: Abstracts, Zomba, Malawi, 02-11 April 1991, pp. 797-812. Malawi.

Pócs T. 1991. The genus Colura in East Africa. Bulletin of the British Bryological Society 57: 33-39.

Pócs T. 1991. The pteridological research of Professor Jan Kornaś in Africa. In: R. OCHYRA \& L. STUCHLIK (eds), Botanostephane Kornasiana. Botanical contributions presented to Jan Kornaś in celebration of his 70th birthday. Pars 1. Fragmenta Floristica et Geobotanica Supplementum 2: 67-70.

Pócs T. 1991. The significance of lower plants in the conservation of Mount Kilimanjaro. In: W. D. NEWMARK (ed.), The Conservation of Mount Kilimanjaro, pp. 24-36. International Union for Conservation of Nature, Cambridge.
Pócs T. 1991. Two new phanerogam species from the Nguru Mountains of Tanzania, East Africa. Fragmenta Floristica et Geobotanica 35: 35-41.

TAn B. C., SAsRTE DE Jesus I. \& PóCs T. 1991. Tropical bryology in peril: a survey. Bryological Times 64: 1-6.

Pócs T., Temu R. A. P. C. \& Minja T. R. A. 1991. Survey of the natural vegetation and flora of the Nguru Mountains. In: I. HEDBERG \& E. PERSSON (eds), Research for Conservation of Tanzanian Catchment Forests: Proceedings from a workshop held in Morogoro, Tanzania, March 13-17, 1989, Morogoro, Tanzania, 13-17 March 1989, pp. 135-149. Uppsala University Press, Sweden.

\section{2}

KnOX E. \& Pócs T. 1992. Lobelia morogoroensis: another Tanzanian giant. Kew Bulletin 47(3): 503-508.

OChYRA R. \& Pócs T. 1992. Bryophyta Africana Selecta. Ser. I-IV. Nos 1-100: Instytut Botaniki PAN, Kraków.

OChYRA R. \& Pócs T. 1992. Bryophyta Africana Selecta: a new exsiccata from Africa. Fragmenta Floristica et Geobotanica 37(2): 379-388.

OChyra R., BednareK-OChyra H., Pócs T. \& Crosby M. R. 1992. The moss Adelothecium bogotense in continental Africa, with a review of its world range. Bryologist 95(3): 287-295.

Pócs T. 1992. Correlation between the tropical African and Asian bryofloras. II. Bryobrothera 1: 35-47.

\section{3}

Born S., FrahM J.-F. \& Pócs T. 1993. Taxonomic results of the BRYOTROP expedition to Zaire and Rwanda. 26. A new checklist of the mosses of Central Africa. Tropical Bryology 8: 223-273.

LovetT J. C. \& Pócs T. 1993. Assessment of the condition of the Catchment Forest Reserves, a botanical appraisal. Ministry of Tourism, Natural Resources and Environment, Dar es Salaam.

OChYRA R. \& Pócs T. 1993. Bryophyta Africana Selecta. Ser. V-VIII. Nos 101-200. Instytut Botaniki PAN, Kraków, $28 \mathrm{pp}$.

Pócs T. 1993. Brothera leana (Sull.) C. Muell., a Laurasian species in tropical Africa. Bulletin du Jardin Botanique National de Belgique 62: 221-224.

Pócs T. 1993. New or little known epiphyllous liverworts, IV. Two new Cololejeuneoideae from the Comoro Archipelago. Journal of the Hattori Botanical Laboratory 74: 45-57.

PÓCS T. 1993. Taxonomic results of the BRYOTROP expedition to Zaire and Rwanda 12. Metzgeriaceae, Plagiochilaceae, Lejeuneaceae (the non epiphyllous collections). Tropical Bryology 8: 105-125. 
Pócs T. \& SZABÓ A. 1993. The epiphytic vegetation on the endemic giant groundsel (Senecio barbatipes) of Mt. Elgon (Kenya). Opera Botanica 121: 189-194.

Tuba Z., Lichtenthaler H. K., Csintalan Z. \& Pócs T. 1993. Regreening of desiccated leaves of the poikilochlorophyllous Xerophyta scabrida upon rehydration. Journal of Plant Physiology 142: 103-108.

\section{4}

OCHYRA R. \& Pócs T. 1994. Bryophyta Africana Selecta: Centuria II. Fragmenta Floristica et Geobotanica 39: 129-135.

Pócs T. 1994. Bryologia Africana trips to Madagascar and other Indian Ocean Islands. Bryological Times 81: 3.

Pócs T., Mizutani M. \& PiIPPo S. 1994. Bryophyte Flora of The Huon Peninsula, Papua New Guinea. LXV. Preliminary contributions on Lejeuneaceae (Hepaticae). 1. Annales Botanici Fennici 31(3): 179-190.

Pócs T. 1994. East African Bryophytes, XIII. Bryophytes from the Bale Mountains, SE Ethiopia. 2. Hepaticae. Fragmenta Floristica et Geobotanica 39: 129-135.

Pócs T. 1994. Less Nándor afrikai mohagyüjtésének eredményei. (Bryophytes collected by Nándor Less in the Ruwenzori Mountains). Botanikai Közlemények 81(1): 110-111.

Pócs T. 1994. New or little known epiphyllous liverworts, V. Aphanolejeunea collected by Barbara M. Thiers in Australia and Papua New Guinea. Hikobia 11: pp. 457-462.

Pócs T. 1994. Taxonomic results of the BRYOTROP expedition to Zaire and Rwanda 27. Lepidoziaceae, II. Tropical Bryology 9: 123-130.

PÓcs T. 1994. Taxonomic results of the BRYOTROP expedition to Zaire and Rwanda 28. Lejeuneaceae, a ramicolous collection. Tropical Bryology 9: 131-136.

ReEse W. D., Magill R. E. \& Pócs T. 1994. Mitthyridium micro-undulatum subsp. comoroensis subsp. nov. from Mayotte. Bryologist 97(4): 430-431.

\section{5}

BABos K., Pócs T. \& FodOR F. 1995. Xylotomy of two endemic Senecio species from Kenya. Acta Botanica Hungarica 39: $235-242$.

Bartha D., Kevey B., Morschhauser T. \& Pócs T. 1995. Plant associations of Hungary [Hazai erdőtársulásaink]. Tilia 1: 8-85.

Pócs T., Piippo S. \& Mizutani M. 1995. Bryophyte flora of the Huon Peninsula, Papua New Guinea. LVI. Preliminary contributions on Lejeuneaceae (Hepaticae). 2. Annales Botanici Fennici 32(4): 259-268.

Pócs T. 1995. East African bryophytes, XIV. Hepaticae from the Indian Ocean Islands. Fragmenta Floristica et Geobotanica 40: 251-277.
Pócs T. 1995. The origin of the foliicolous bryoflora in Indian Ocean Islands. In: IAB \& IAL Symposium of Foliicolous Cryptogams, Eger, Hungary, 29-02 September 1995. Eger.

Pócs T. \& RAISz RózsA V. (eds) 1995. Eszterházy Károly Tanárképző Főiskola tudományos közleményei. Acta Academiae Paedagogicae Agriensis. Sectio Historiae. EKF Líceum Kiadó, Eger.

Tuba Z., Csintalan Zs., Szente K., Nagy Z., LichtenthaLer H. K. L., Maróti I., Grace J., Proctor M. C. F., SMIRNOFF N., MASAROVICOVÁ E., LAITAT E., TAKÁCS Z., KemÉNy G., BADACSONYi A., Pócs T. \& FeKete G. 1995. Desiccation and revival of desiccation tolerant plants at present and elevated $\mathrm{CO}_{2}$. Bulletin of the University of Agricultural Sciences (Gödöllö) 2: 83-91.

\section{6}

Pócs T. 1996. A new book helping African bryology: Grolle, R.: The hepaticae and Anthocerotae of the East African Islands. An Annotated Catalogue. Bryophytorum Bibliotheca 48. Bryological Times 87: 6.

Pócs T. 1996. Andreánszky Gábor növényföldrajzi munkássága (The phytogeographical work of Gábor Andreánszky). In: L. HABLY (ed.), Emlékkötet: Andreánszky Gábor (18951967) születésének 100. évfordulója alkalmából rendezett emlékülés elöadásainak anyagából, pp. 45-48. Magyar Természettudományi Múzeum, Budapest.

Pócs T. 1996. Epiphyllous liverwort diversity at worldwide level and its threat and conservation. Anales del Instituto de Biologia Universidad Nacional Autonóma de México. Serie Botanica 67: 109-127.

Pócs T. 1996. The Hepaticae and Anthocerotae of the East African Islands: An annotated catalogue. Bryophytorum Bibliotheca 48. Journal of Bryology 19: 198-199.

\section{7}

Dulai S., MolnÁR I., LeHOCZKI E. \& Pócs T. 1997. The role of photosynthetic activity in the vulnerability of an insular biome to invasion by alien species. In: G. GARAB (ed.), Photosynthesis: mechanisms and effects: Proceedings of the XIth International Congress on Photosynthesis, Budapest, Hungary, August 17-22, 1998, pp. 4057-4060. Kluwer Academic Publishers, Dordrecht.

FARKAS E. \& PÓcs T. (eds) 1997. Cryptogams in the phyllosphere: systematics, distribution, ecology and use. In: Proceedings of the IAB and IAL Symposium on Foliicolous Cryptogams. ELTE Eötvös Kiadó, Budapest.

FARKAS E. \& Pócs T. 1997. Preface. Abstracta Botanica 21: 3 .

KIS G. \& Pócs T. 1997. Oil body studies on African Hepaticae. Journal of the Hattori Botanical Laboratory 81: $175-242$. 
KIS G. \& PócS T. 1997. The living plant collection and its database at Károly Eszterházy College [Az egri Eszterházy Károly Tanárképző Főiskola Élőnövény-gyüjteménye és annak nyilvántartása]. In: I. MABosz, Informatikai Szimpózium. 1997, december 10. A Szimpózium elöadásainak összefoglalója: A Szimpózium elöadásainak összefoglalója, pp. 9-10.

LyE K. A. \& Pócs T. 1997. New records and additions to the hepatic flora of Uganda. Lidia 4: 13-36.

Pócs T. 1997. Bryophyte diversity along the Eastern Arc. In: N. NuMMELIN (ed.), International Conference on the Eastern Arc Mountains, Morogoro, Tanzania, 1-5 December 1997, pp. 22-23. Morogoro, Tanzania.

Pócs T. 1997. New or little known epiphyllous liverworts, VI. Papillolejeunea gen. nov. from Papua New Guinea. Tropical Bryology 13: 1-18.

Pócs T. 1997. New or little known epiphyllous liverworts, VII. Two new Lejeuneaceae species from the Mascarene Islands. Cryptogamie - Bryologie Lichenologie 18: 195-205.

Pócs T. 1997. Preface. In: P. P. DuARTE, Musgos de Cuba. Fontqueria 47: 6.

Pócs T. 1997. The distribution and origin of the foliicolous bryophyta in the Indian Ocean Islands. Abstracta Botanica 21: 123-134.

Pócs T. \& LÜCKING A. 1997. The genus Aphanolejeunea A. Evans in the Guianas. Haussknechtia 7: 26-27.

Pócs T. \& TóTHMÉRÉSz B. 1997. Foliicolous bryophyte diversity in tropical rainforests. Abstracta Botanica 21(1): 135-144.

\section{8}

LEON Y., Pócs T. \& Rico R. R. 1998. Records on bryophyte flora of the Venezuelan Andes, I. Cryptogamie - Bryologie Lichenologie 19(1): 1-25.

LEÓN Y. V., Pócs T. \& Rico R. R. R. 1998. Registros para la brioflora de los Andes Venezolanos, I. Cryptogamie Bryologie Lichenologie 19: 15-39.

Pócs T. 1998. Bryophyte diversity along the Eastern Arc. Journal of East African Natural History 87: 75-84.

\section{9}

EQuinua C. \& Pócs T. 1999. Epiphyllous bryophytes from the Lacandon Forest, Chiapas, Mexico. Bryologist 102(4): 747-752.

Hodgetts N. G. \& Pócs T. 1999. British Bryological Society Expedition to Mulanje Mountain, Malawi. 10. Lepidoziaceae (Hepaticae). Journal of Bryology 21: 316-318.

Infante M., Heras P. \& Pócs T. 1999. Bryophytes from the Republic of Equatorial Guinea (West Central Africa). V. Diplasiolejeunea cogoensis sp. nov. Tropical Bryology 17: 9-12.
Pócs T. 1999. A löszfalak virágtalan növényzete I. Orografikus sivatag a Kárpátmedencében. (Studies on the cryptogamic vegetation of loess cliffs, I. Orographic desert in the Carpathian Basin). Kitaibelia 4: 143-156.

Pócs T. 1999. Bryophyte speciation and diversity in the East African mountains. Bryobrothera 5: 237-245.

Pócs T. 1999. Trachylejeunea grolleana, a new representative of the Neotropical subgenus Hygrolejeuneopsis in Madagascar. Haussknechtia 9: 283-290.

Pócs T. \& EGGERs J. 1999. New or little known epiphyllous liverworts, VIII. Two new Papillolejeunea species from Papua New Guinea. Bryobrothera 5: 159-164.

Pócs T. \& LYE K. A. 1999. New records and additions to the hepatic flora of Uganda 2. Tropical Bryology 17: 23-33.

Pócs T. \& PIIPPO S. 1999. Bryophyte flora of the Huon Peninsula, Papua New Guinea. LIV. Aphanolejeunea (Lejeuneaceae, Hepaticae). Acta Botanica Fennica 165: 85-102.

Pócs T. \& Streimann H. 1999. Epiphyllous liverworts from Queensland, Australia. Bryobrothera 5: 165-172.

\section{0}

Dulai S., Pócs T., Orbán S., LehoczKi E. \& MolnÁr I. 2000. Some photosynthetic characteristics of an idigenous (Cyathea glauca) and an introduced (Psidium cattleyanum) plant species in Réunion Island. Plant Physiology and Biochemistry 38(Supplement): S237.

Hodgetts N., O’SheA B. \& Pócs T. 2000. Sub-Saharan Africa. Biodiversity, centres of diversity, and endemism. In: T. HÄllingBACK \& N. HodgetTS (eds), Status Survey and Conservation Action Plan for Bryophytes. Mosses, Liverworts and Hornworts, pp. 31-34. IUCN, Gland.

KIs G., Pócs T. \& SzABÓ A. 2000. Plant collections of Károly Eszterházy College (Az Eszterházy Károly Főiskola növénygyüjteményei). In: S. ORBÁN (ed.), 50 éves a biológia oktatás Egerben. (Magyar Tudomány Napja '99 Konferencia elöadásainak összefoglalói), Nyiregyháza, Hungary, 3-5 November 1999, pp. 40-41. Eszterházy Károly Főiskola Biológiai és Környezettudományi Intézet, Eger.

Pócs T. 2000. Aphanolejeunea. In: R. SCHUMACKER \& J. VÁŇA (eds), Identification keys to the liverworts and hornworts of Europe and Macaronesia: distribution and status, pp. 3940. Hautes-Fagnes Scientific Station, Robertville.

Pócs T. 2000. 50 years of botanical research at the Department of Botany of the Károly Eszterházy College [Botanikai kutatások 50 esztendeje az Egri Tanárképző Főiskola Növénytani Tanszékén]. In: S. ORBÁN (ed.), 50 éves a biológia oktatás Egerben. (Magyar Tudomány Napja '99 Konferencia elöadásainak összefoglalói), Nyíregyháza, Hungary, 3-5 Nvember 1999, pp. 34-36. Eszterházy Károly Főiskola Biológiai és Környezettudományi Intézet Eger.

Pócs T. 2000. Remarks on the origin of drought tolerant plants. [Gondolatok szárazságtürő növényeink származásáról]. In: K. VIRÁGH \& A. Kun (eds), Vegetáció és dinamizmus. 
A 70 éves Fekete Gábort köszöntik tanitványai, barátai és munkatársai, pp. 239-242. MTA Ökológiai és Botanikai Kutatóintézet, Vácrátót.

Pócs T. 2000. Renauldia lycopodioides Bizot ex Pócs. Status: Endangered (EN) (B1, 2c,d). In: T. HÄLliNGBACK \& N. HodgetTs (eds), Status Survey and Conservation Action Plan for Bryophytes. Mosses, Liverworts and Hornworts, p. 34. IUCN, Gland.

TAN B. \& PÓCS T. 2000. Bryogeography and conservation of bryophytes. In: A. J. SHAW \& B. GOFFINET (eds), Bryophyte biology, pp. 403-448. Cambridge University Press, Cambridge.

\section{1}

Brown E. A. \& Pócs T. 2001. A new species of Radula sect. Cavifolium (Radulaceae: Hepaticae) from Queensland, Australia. Telopea 9: 435-438.

KIS G. \& Pócs T. 2001. What is Chondriolejeunea? Cryptogamie - Bryologie 22(4): 237-246.

Pócs T. 2001. East African bryophytes, XVI. New taxa of Lejeuneoideae (Lejeuneaceae) collected by Patricia Geissler in Manongarivo Special Reserve, NW Madagascar. Candollea 56(1): 69-78.

Pócs T. 2001. Rare and endangered moss species of loess cliffs in the Danube Basin. In:The 4rd European Conference on the Conservation of Bryophytes Abstracts, Prühonice, Czech Republic, 2001. Průhonice.

Pócs T. \& VÁŇA J. 2001. A new species of Amphicephalozia (Hepaticae) from Madagascar. Polish Botanical Journal 46(2): 145-150.

\section{2}

Benkö Zs., JuhÁsz A., Pócs T. \& TuBA Z. 2002. Desiccation survival times in different desiccation-tolerant plants. Acta Biologica Szegediensis 46: 231-233.

Borhidi A., FARKAS E. \& Pócs T. 2002. Research on Taxonomy and Tropical ecology [Taxonómiai és trópusi ökológiai kutatások]. In: G. FeKETE, K. T. KISS, E. KovÁCSNÉ LÁNG, A. Kun, J. NoseK \& A. RÉvÉSz (eds), A Magyar Tudományos Akadémia Ökológiai és Botanikai Kutatóintézete 50 éve 1952-2002, pp. 209-227. MTA Ökológiai és Botanikai Kutatóintézet, Vácrátót.

Dulai S., Pócs T., Orbán S., LehoczKi E. \& Molnár I. 2002. The photosynthesis-ecophysiological chracterisation of an indigenous (Cyathea glauca Bory) and an introduced (Psidium cattleianum Sabine) plant species in Réunion Island. Acta Academiae Paedagogicae Agriensis Nova Series - Sectio Biologiae 23: 155-163.

KÜRSCHNER H. \& PÓCS T. 2002. Bryophyte communities of the loess cliffs of the Pannonian basin and adjacent areas, with the description of Hilpertio velenovsky-Pterygoneuretum compacti ass. nov. Studies on the cryptogamic vegetation of loess cliffs, VI. Nova Hedwigia 75(1-2): 101-119.
MÜLLER F. \& PÓCS T. 2002. Contribution to the hepatic flora of Rodrigues (East African islands). Tropical Bryology 22: $107-113$.

PiIppo S., He X. L., Juslen A., Tan B. C., Murphy D. H. \& Pócs T. 2002. Hepatic and hornwort flora of Singapore. Annales Botanici Fennici 39(2): 101-127.

Pócs T. 2002. Cololejeunea attilana sp. nov. from Tanzania (East African bryophytes, XVII). In: É. SALAMON-ALBERT (ed.), Magyar botanikai kutatások az ezredfordulón: Tanulmányok Borhidi Attila 70. születésnapja tiszteletére, pp. 127-133. PTE Növénytani Tanszék, Pécs.

Pócs T. 2002. East African bryophytes XVIII. Two new Lejeuneaceae (Hepaticae) from the Aberdare Mountains (Kenya). Polish Botanical Journal 47(1): 11-20.

Pócs T. 2002. New or little known epiphyllous liverworts, IX. Two new neotropical Cololejeunea species. Acta Botanica Hungarica 44(3-4): 371-382.

Pócs T., Geissler P., SAss-Gyarmati A., Kis G. \& Orbán S. 2002. The bryophytes collected in the Réserve Spéciale de Manongarivo, Madagascar. In: L. GAUTIER \& X. GOODMAN (eds), Inventaire Floristique et Faunistique de la Réserve Spéciale de Manongarivo (NW Madagascar). Boissiera 59: 41-76.

Pócs T., Goia I., Kis G., Orban S., SASS-Gyarmati A., van ZANTEN B. O. 2002. Hilpertia velenovsky (Schiffn.) Zander and other pottioid mosses (Bryophyta) new to Romania. Studies on the cryptogamic vegetation on loess cliffs, IX. Contribuţii Botanice 37: 13-24.

Sass-Gyarmati A. \& Pócs T. 2002. A second species of Symbiezidium from Africa. Cryptogamie - Bryologie 23(1): 31-39.

\section{3}

Chuah-Petiot M. \& Pócs T. 2003. East African Bryophytes XIX. A contribution to the bryoflora of Kenya. Acta Botanica Hungarica 45: 53-64.

Molnár I., Orbán S., Pócs T., Sass-Gyarmati A., LeHOCZKI A. \& DUlAI S. 2003. Photosynthetic responses of Mastigophora diclados (Brid. ex Web.) Nees ecotypes of excess light consequence of their microhabitats in Réunion Island a fluorescens induction study. Acta Academiae Paedagogicae Agriensis Nova Series - Sectio Biologiae 24: 215-235.

Pócs T. 2003. Aphanolejeunea. In: S. R. GRADSTEIN \& D. P. DA Costa (eds), The Hepaticae and Anthocerotae of Brazil. Memoirs of New York Botanical Garden 87: 107-112.

Pócs T. 2003. Cololejeunea. In: S. R. GRAdSTEIn \& D. P. DA Costa (eds), The Hepaticae and Anthocerotae of Brazil. Memoirs of New York Botanical Garden 87: 130-135.

Pócs T., HorvÁth A., GÁNTI T., BÉrCZI SZ. \& SZATHMÁRY E. 2003. On the basis of terrestrial analogue site studies are the dark dune spots remnants of the crypto-biotic-crust of Mars? In: 38th Vernadsky-Brown Microsymposium on 
Comparative Planetology, Moscow, Russia, 25 October - 9 November 2003, Paper 079. Moscow.

\section{4}

HeinRIChs J., LindNER M. \& PÓcs T. 2004. nrDNA internal transcribed spacer data reveal that Rhodoplagiochila R.M. Schust. (Marchantiophyta: Jungermanniales) is a member of Plagiochila sect. Arrectae Carl. Organisms Diversity \& Evolution 4(1-2): 109-118.

Heinrichs J., Groth H., Lindner M., Renker C., Pócs T. \& PROSCHOLD T. 2004. Intercontinental distribution of Plagiochila corrugata (Plagiochilaceae, Hepaticae) inferred from nrDNA ITS sequences and morphology. Botanical Journal of the Linnean Society 146(4): 469-481.

HorvÁth A., GÁNTI T., PÓCS T., BÉRCZI Sz. \& SZATHMÁRY E. 2004. Astrobiology on Mars. In: 35th COSPAR Scientific Assembly. Held 18-25 July 2004, Paris, France, p. 4215. http://adsabs.harvard.edu/abs/2004cosp...35.4215H.

Horváth A., PÓcs T., GÁNTI T., BÉrCZI Sz. \& SZATHMÁRY E. 2004. On the possibility of a crypto-biotic crust on Mars based on northern and southern ringed polar dune spots. In: 35th Lunar and Planetary Science Conference, Houston, United States of America, 15-19 March 2004. http://www. 1pi.usra.edu/meetings/lpsc2004/pdf/1914.pdf.

Horváth A., Bérczi Sz., Kereszturi Á., Pócs T., Gesztesi A., GÁNTI T. \& SZATHMÁry E. 2004. Annual change of outflows from dark dune spots in the southern polar region of the Mars In: The 4th European Workshop on Exo/Astrobiology „Life in Extreme Environments”, 22-25 November 2004, Milton Keynes, England. http://physics.open.ac.uk/ eana/POSTERS/Session2.

Horváth A., Bérczi Sz., GÁnti T., Gesztesi A., Pócs T., SZATHMÁRY E., MANRUBIA S. C, FERNÁNDEZ-REMOlAR D. \& BALlesteros O. P. 2004. DS-test in the Northern Polar Region: A proposal for Mars Express. In: EGU 1st General Assembly. Nice, Italy, 2004. Nice, Italy.

Lindner M., Pócs T. \& HeINRICHS J. 2004. On the occurrence of Plagiochila stricta on Madagascar, new to Africa. Journal of the Hattori Botanical Laboratory 96: 261-271.

Pócs T. 2004. New or little known epiphyllous liverworts, XI. Otolejeunea subana sp. nov. from Madagascar. Acta Academiae Paedagogicae Agriensis Nova Series - Sectio Biologiae 25: 49-57.

Pócs T., Horváth A., GÁnti T., BÉrczi Sz. \& SZATHMÁRy E. 2004. Possible Crypto-Biotic-Crust on Mars? In: R. A. HARris \& L. OUWEHAND (comp.), Proceedings of the III European Workshop on Exo-Astrobiology - Mars: The Search for Life, 18-20 November 2003, Madrid, Spain, pp. 265-266. European Space Agency, Noordwijk.

Pócs T., Sabovljević M., Puche F., Moragues J. G. S., Gimeno C. \& KÜRSCHNER H. 2004. Crossidium laxefilamentosum Frey \& Kurschner (Bryopsida: Pottiaceae), new to Europe and to North Africa. Journal of Bryology 26: 113-124.
Pócs T., Szathmáry E., Bérczi Sz., HorvÁth A., GÁNTI T. \& KereszTURI Á. 2004. Criptobiotic crust types, as earthy analogues of possible Martian life forms. The 4th European Workshop on Exo/Astrobiology „Life in Extreme Environments", 22-25 November 2004, Milton Keynes, England. http://physics.open.ac.uk/eana/TALKS.

Rico R. \& Pócs T. 2004. Bryophytes from high lands of Venezuelan Guyana: hepatics of Roraima-tepui I. Cryptogamie - Bryologie 25(3): 249-269.

\section{5}

Ahonen I., SASS-Gyarmati A. \& PÓcs T. 2004. Molecular, morphological and taxonomic evaluation of the Ptychanthus striatus (Lejeuneaceae, Marchantiophyta) complex. Acta Botanica Hungarica 47(3-4): 225-246.

Bérczi Sz., Horváth A., NAGy B., Kereszturi Á., SiK A., Pócs T., Gesztesi A., GÁnti T. \& SzAThmáry E. 2005. Comparisons of Martian flow-streaks with DDS origin and their probable counterparts on Antarctica. In: 29th Symposium on Antarctic Meteorites held at the National Institute of Polar Research, Tokyo, Japan, June 7-9, 2005, pp. 3-4. Paper National Institute of Polar Research, Tokyo.

Horváth A., Kereszturi Á., Bérczi Sz., SiK A., Pócs T., GeszTesi A., GÁNTI T. \& SzAThMÁRY E. 2005. Annual change of Martian DDS-seepages. In: 36th Lunar and Planetary Science Conference, Houston, United States of America, 14-18 March 2005, p. 1128. http://www.Ipi.usra. edu/meetings/lpsc2005/pdf/1128.pdf.

GÁnti T., Pócs T., BÉrczi Sz., Ditrió-Puskás Z., GÁLSólymos K., Horváth A., Nagy M. \& Kubovics I. 2005. Morphological investigations of Martian spherules, comparisons to collected terrestrial counterparts: In: 36th Lunar and Planetary Science Conference, Houston, United States of America, 14-18 March 2005, p. 2026. http://www. 1pi.usra.edu/meetings/lpsc2005/pdf/2026.pdf.

Pócs T. 2005. The signs of global warming in the Hungarian bryophyte flora [A globális felmelegedés jelei hazánk mohaflórájában]. In: F. JORDÁN (ed.), A DNS-töl a Globális Felmelegedésig. A 70 éves Vida Gábor köszöntése, pp. 149-156. Scientia, Budapest.

Pócs T. 2005. Activities in tropical bryology at the Eszterházy College, Eger, Hungary (EGR) during 2004-2005. Bryological Times 116: 6.

Pócs T. 2005. Aerophytic cyanobacteria from the Mții Apuşeni (Romanian Western Carpathians, Transylvania), I.: The epilithic crusts at the entrance of Huda lui Papară Cave. Kanitzia 13: 99-108.

Pócs T. 2005. East African bryophytes, XV. The occurrence of Bryum laevigatum (Bryaceae, Bryophyta) in Africa. Polish Botanical Journal 49(2): 117-121.

Pócs T. 2005. Syzygiella riclefii sp nov. (Marchantiophyta, Jungermanniaceae) from the Andes of Merida. Registros Para la Bryoflora de Los Andes Venezolanos, II. Cryptogamie-Bryologie 26(1): 41-48. 
Pócs T. \& NinH T. 2005. Contribution to the bryoflora of Vietnam, VI. On the liverwort flora of Vu Quang Nature Reserve. Acta Botanica Hungarica 47(1-2): 151-171.

Pócs T., Szathmáry E., Horváth A., Nagy B., Sik A., BÉrCzi Sz., GÁNTI T. \& KereszTuri Á. 2005. Extremophile cryptobiotic communities in cold and hot deserts. In: 5th EANA Workshop. In: EANA 5th European Workshop on Astrobiology, Budapest, Hungary, 10-12 October 2005. Budapest.

SASS-Gyarmati A., Pócs T. \& ORBÁN S. 2005. Contribution to the knowledge of the bryoflora of Detunata Natural Reserve (Metaliferi Mountains, Transylvania). Studia Botanica Hungarica 36: 123-130.

Sass-Gyarmati A., Molnár K., Orbán S., Pócs T. \& ERZBERGER P. 2005. The cryptogamic flora of the Zgurasti Cave and surroundings (Apuseni Mountains, Romania). In: Proceedings of 17th International Botanical Congress. Vienna, Austria, 17-23 July 2005, p. 619. Vienna.

SzATHMÁry E., Horváth A., GÁNTi T., BÉrCZI Sz., Pócs T., GeszTEsi A., Kereszturi Á. \& SiK A. 2005. Candidates for Organisms on Mars on the basis of DDS, CBC, Desert varnish and cryoconite studies: In: 1st Mars Express Science Conference, 21-25 February 2005, Noordwijk, Netherlands, Noordwijk, Abstract book, p. 118. http://sci2.esa. int/Mars/MarsExpressConference2005.pdf.

Szathmáry E., Horváth A., Sik A., Bérczi Sz., Gánti T., Pócs T., KERESZTURi Á. 2005. Signs of water runoff and its relation to possible living organisms on Mars. In: EANA 5th European Workshop on Astrobiology, Budapest, Hungary, 10-12 October 2005. Budapest.

\section{6}

Dauphin L. G., Pócs T., Villareal J. C. \& Salazar Allen N. 2006. Nuevos registros de Hepáticas y Anthocerotófitas para Panamá. Tropical Bryology 27: 73-85.

GÁNTI T., BÉrCzi Sz., HorvÁth A., KERESZTURi Á., Pócs T., SIK A. \& SZATHMÁRY E. 2006. Hypothetical time sequence of morphological changes in global and local levels of the dark dune spots in Polar region of Mars. In: Proceedings of the 37th Lunar and Planetary Science Conference League City, Texas, United states of America, March 13-17, 2006, Abstract p. 1918. http://www.lpi.usra.edu/ meetings/lpsc2006/pdf/1918.pdf

HorvÁth A., GÁNTI T., BÉRCZI Sz., Pócs T., KereszTuri Á. \& SIK A. 2006. Dark dune patches on Mars: the possibility of life on Mars? [Marsi sötét dünefoltok: az élet lehetősége a Marson?] Magyar Tudomány 167(11): 1357-1375.

KIS G. \& Pócs T. 2006. Supplementum and corrections of the non European types and list of exsiccata in the Eger Cryptogamic Herbarium (EGR). Folia Historico-Naturalia Musei Matraensis 30: 35-41.

Péli E., Nie L., Pócs T., Poremski S. \& Tuba Z. (eds) 2006. Ecophysiological features of some species of tropical drought stress tolerant vegetation [Trópusi kiszáradástürő kriptogám vegetáció néhány fajának ökofiziológiai vonatkozásai]. In: VII. Magyar Ökológus Kongresszus, Budapest, Magyarország 4-6 September 2006, pp. 4-6. Budapest.

Pócs T. 2006. A sixth species of Pictolejeunea (Jungermanniopsida) from the Venezuelan Guyana. Acta Botanica Hungarica 49(1-2): 109-119.

Pócs T. 2006. Bryophyte colonization and speciation on oceanic islands: an overview. Lindbergia 31: 54-62.

Pócs T. 2006. Contributions to the bryoflora of Australia, II.: On the Australasian „Tuyamaelloideae” (Lejeuneaceae), with the description of Austrolejeunea occidentalis. Journal of the Hattori Botanical Laboratory 99: 185-195.

Pócs T. 2006. Data to the knowledge of the bryophyte flora in Transylvanian Mountains (Adatok az Erdélyi Szigethegység mohaflórájának ismeretéhez). In: T. KALAPOS (ed.), Jelez a flóra és a vegetáció. A 80 éves Simon Tibort köszöntjük, pp. 9-24. Scientia, Budapest.

Pócs T. 2006. East African bryophytes, XX. Observations on some Calypogeiaceae. Acta Academiae Paedagogicae Agriensis Nova Series - Sectio Biologiae 25: 29-35.

Pócs T. 2006. East African bryophytes. XXI. Two new species of Telaranea, sect. Tenuifoliae and records on Amazoopsis from the Indian Ocean Islands. Acta Botanica Hungarica 48(1-2): 105-124.

Pócs T. 2006. East African bryophytes, XXII. Two new species, Plagiochila artsii and Plagiochila hiroshiana (Plagiochilaceae, Marchantiophyta). Journal of the Hattori Botanical Laboratory 100: 333-350.

Pócs T. 2006. New or little-known epiphyllous liverworts, X. On two neotropical Diplasiolejeunea species. Bryologist 109(3): 408-414.

Pócs T. 2006. Remarks on the Flora of Southwestern Hungary in connection with the publication of the $8^{\text {th }}$ volume [Gondolatok a Délnyugat-Dunántúl flórája VIII. részének kiadása kapcsán]. Kanitzia 14: 241-242.

Pócs T. 2006. The role of cryptobiotic layer in terrestrial ecosystems [A kryptobiotikus kéreg és szerepe a szárazföldi ökoszisztémákban] In: E. Sz. Vızi (ed.), Székfoglalók a Magyar tudományos Akadémián, 2001, Élettudományok, pp. 439-478.

Pócs T. \& EGgERs J. 2006. New or little known epiphyllous liverworts, XIII. Cololejeunea arfakiana sp. nov. from West Irian (New Guinea). Polish Botanical Journal 51(2): $155-158$.

Pócs T. \& SAss-Gyarmati A. 2006. New or little known epiphyllous liverworts, XII. Archilejeunea helenae Pocs \& Gyarmati, sp. nova. Cryptogamie - Bryologie 27(1): 103-109.

PÓcs T. \& SCHÄFER-VERWIMP A. 2006. East African bryophytes, XXIII. Three new species of Diplasiolejeunea (Le- 
jeuneaceae, Jungermanniopsida) from Madagascar. Cryptogamie - Bryologie 27(4): 439-452.

Pócs T. \& StReimanN H. 2006. Contributions to the bryoflora of Australia, I. Tropical Bryology 27: 19-24.

Pócs T., NAIR M., Rajesh K. P. \& Madhusoodanan P. V. 2006. Liverwort (Marchantiopsida) records from the Western Ghats (Kerala State, Peninsular India). Acta Botanica Hungarica 49(1-2): 121-129.

Pócs T., GÁnti T., Horváth A., Bérczi Sz., Kereszturi A., SiK A., SZATHMÁRY E. 2006. Comparison of the cryptobiotic crusts and surface mineral crusts according to their main characteristics in helping life support mechanisms and their implied role for Martian living organisms: In: Proceedings of the 30th Conference on Antarctic Meteorites, Tokyo, Japan, 6-8 June 2006, pp. 99-100. Tokyo.

Seaward M. R. D., Ellis L. T., Pócs T. \& Wigginton M. J. 2006. Bryophyte flora of the Chagos Archipelago. Journal of Bryology 28(1): 11-19.

Tuba Z., Csintalan Zs., Balogh J., CzÓBel Sz., PÉli E., Pócs T., Porembski S. \& Georgieva K. 2006. Plant drought stress and tropical Inselberg ecophysiology : poicylohydric water transport and plant physiology based on different photosynthetic structures from the known ones. (Növényi kiszáradás és trópusi Inselberg-ökofiziológia: poikilohidrikus vízgazdálkodásra és az ismertektől eltérő fotoszintetikus szerkezetekre épülő növényi müködés). In: VII. Magyar Ökológus Kongresszus, Budapest, 2006, szeptember 4-6, p. 215. University Publisher ELTE, Budapest

\section{7}

Bérczi Sz., Pócs T., Horváth A., GÁnti T, Kereszturi Á., SiK A. \& SZAThmáry E. 2007. Possibility of transient liquid water on the dark subpolar dune fields of Mars: In: 31st NIPR Symposium Antarctic Meteorites, Tokyo, Japan, 5-7 June 2007, pp. 7-8. http://planetologia.elte. $\mathrm{hu} /$ berczi2.pdf

Horvath A, Kereszturi A, Sik A, Bérczi Sz., Ganti T, Pócs T. \& SzATHMARY E. 2007. Investigations of Martian seepages originated from Dark Dune Spots (DDS). In: Space Week. Conference, Moscow, Russia, 04/08/200709/08/2007. Moscow.

MÜLlER F. \& PóCS T. 2007. A contribution to the knowledge of epiphyllous bryophytes of Bioko Island (equatorial Guinea), including additional remarks on non-epiphyllous species. Journal of Bryology 29: 81-94.

Péli E., Laufer Zs., Nie L., Tuba Z., Pócs T. \& Porembski S. 2007. Ecophysiology of desiccation-tolerant cyanobacterial cryptobial crusts of tropical inselberg: chlorophyll fluorescence and $\mathrm{CO}_{2}$ assimilation responses to rehydration followed prolonged air-dried period. In: Indo-hungarian scientific workshop, Biology of Inselberg plants, Ecology and machanism of desiccation tolerant plants and veetation in tropical inselberg 16-24 March 2007, Bareilly Collage, Bareilly, India. Bareilly Collage, Bareilly.

Pócs T. 2007. A new species of Impatiens (Balsaminaceae) from the Nguru Mountains (Tanzania). Acta Botanica Hungarica 49(3-4): 377-383.

Pócs T. 2007. Bryophyte communities at the edge of Tunisian Sahara, with the description of Gymnostomum viridulum Brid. subsp. saharae, subsp. nov. (Pottiaceae, Bryophyta). Nova Hedwigia 131: 101-120.

Pócs T. 2007. Bryophytes from Fiji Islands, I. Hymenodon chenianus Pócs, sp. n. (Rhizogoniaceae) and Ephemeropsis tjibodensis Goebel. Chenia 9: 25-38.

Pócs T. 2007. Few thoughts about the conservation of cryptogamic plants worldwide and in Romania. Buletinul Gradinii Botanice Iasi 14: 137.

Pócs T. 2007. On the Research Group for Bryology of the Hungarian Academy of Sciences at the Eszterházy College, Eger, Hungary. Bryological Times 124: 11-13.

Pócs T. \& EGGERS J. 2007. Bryophytes from the Fiji Islands, II. An account of the genus Colura, with the description of C. vitiensis sp. nov. Polish Botanical Journal 52(2): 81-92.

Pócs T. \& LUKE Q. 2007. A new species of Encephalartos (Zamiaceae) from Tanzania. Journal of East African $\mathrm{Na}$ tural History 96(2): 193-201.

Pócs T. \& LuKE Q. 2007. East African bryophytes, XXV. Bryological records from the Chyulu Range, Kenya. Journal of East African Natural History 96: 27-46.

Pócs T. \& SASs-Gyarmati A. 2007. Flowers of the Mountains of Transylvania. (Az Erdélyi szigethegység virágai\}. Magánkiadás, Eger.

Pócs T., Pócs S., Chuah-Petiot M. S., Malombe I. \& MASINDE S. 2007. East African bryophytes, XXIV. Records from the dry lands of Kenya, with a description of Didymodon revolutus var. nov. africanus (Pottiaceae). Lindbergia 32: 33-39.

Pócs T., HorvÁth A., GÁNTI T., BÉrCZI Sz., KereszTuri Á., SíK A. \& SZATHMÁRY E. 2007. Comparison of surface mineral crusts and cryptobiotic-crusts: how can they help life support mechanisms; implications to living organisms on Mars. In: 38th Lunar and Planetary Science Conference, League City, United States of America, 12-16 March 2007. Lunar and Planetary Institute, Paper 1144. http://www.lpi. usra.edu/meetings/lpsc2007/pdf/1144.pdf.

Sass-Gyarmati A., Goia I. \& Pócs T. 2007. The distribution of Metzgeria violacea (Ach.) Dumort in the Apuseni Mountains (Romanian Western Carpathians). In: European Committee for the Conservation of Bryophytes -7 th Conference. Bryophyte Conservation. Kolozsvár, Romania, 2-7 September 2007, p. 13. Kolozsvár.

Szathmáry E., Bérczi Sz., Pócs T., Horváth A., Gánti T., KERESZTURI Á. \& SIK A. 2007. Ephemeral conditions for 
life at the South Polar Region of Mars. In: 2nd European Planetary Science Congress, Potsdam, Germany, 20-24 August 2007. EPSC Abstracts, EPSC2007-A-00162. http:// www.cosis.net/abstracts/EPSC2007/00162/EPSC2007J-00162.pdf.

Szathmáry E., GÁnti T., Pócs T., HorvÁth A., Keresztúri Á., BÉRCZI Sz. \& SíK A. 2007. Life in the dark dune spots of Mars: a testable hypothesis. In: R. PudRITZ, P. HigGS \& J. STONE (eds), Planetary systems and the origins of life, pp. 241-262. Cambridge University Press, Cambridge.

Tuba Z., CsinTalan Zs. \& Pócs T. 2007. A növényi kiszáradástürés homoioklorofill éa poikiloklorofill stratégiája és a trópusi szigethegy-ökofiziológia. Magyar Tudomány 168(10): 1250-1257.

Tuba Z., Lei N., Peli E., Pócs T., Porembski S. \& Laufer Z. 2007. Chlorophyll fluorescence and $\mathrm{CO}_{2}$ assimilation of desiccation-tolerant cyanobacterial crustaceous layer of tropical inselberg rock surfaces after rehydration following one and four-year air-dried stage. South African Journal of Botany 73: 500-501.

\section{8}

Buczkó K., Wojtal A. Z. \& Pócs T. 2008. Exsiccata Carpatopannonica, Collectio Diatomologica. Mires. Fasc. I. nos 1-9. Hungarian Natural History Museum, Budapest.

Horváth A., Kereszturi Á., BÉrczi Sz., SiK A., GÁNTI T., Pócs T., Kuti A. \& SZATHMÁry E. 2008. Seepage phenomena originating from Dark Dune Spots at southern and northern polar region of Mars. In: 3rd Planetology Seminar, Budapest, Hungary, 2-4 September 2008. http:// planet-veab.elte.hu/psz3/p1.pdf

Kereszturi A., Berczi Sz., Horvath A., Ganti T., Kuti A., Pócs T., SiK A. \& SZATHMÁRY E. 2008. North-south comparison of springtime dark slope structures on Mars, and the possibility of liquid water. In: European Planetary Science Congress, Münster, Germany, 21-26 September 2008, EPSC Abstracts, EPSC2007-A-00162. http://meetings.copernicus.org/epsc2008/crawl/abstracts/ EPSC2008/00386/EPSC2008-A-00386-1.

Kereszturi Á., Möhlmann D., Bérczi Sz., GÁnti T., HorvÁth A., KuTi A., Pócs T., SiK A. \& SZATHMÁRY E. 2008. Analysis of possible interfacial water driven seepages on Mars. In: 39th Lunar and Planetary Science Conference, Houston, United States of America, 10-14 March 2008. Paper 1555. http://www.lpi.usra.edu/meetings/lpsc2008/ pdf/1555.pdf

Kereszturi Á., Möhlmann D., Bérczi Sz., GÁnti T., Horváth A., Kuti A., Pócs T., SiK A. \& Szathmáry E. 2008. Seepage phenomena on Mars at subzero temperature. In: 37th COSPAR Scientific Assembly, Montreal, Canada, 13-20 July 2008. Paper P106-ThuFri B02-0050-08. http:// adsabs.harvard.edu/abs/2008cosp...37.1497K.
Pócs T. 2008. British Bryological Society Expedition to Mulanje Mountain, Malawi. 19. Metzgeriaceae and other unpublished records. Tropical Bryology 29: 1-3.

Pócs T. 2008. Bryophytes from the Fiji Islands, III. The genus Phaeolejeunea Mizut., with the detailed description of P. amicorum (Hürl.) Pócs, stat. nov. Fieldiana Botany 47: $139-145$.

Pócs T. 2008. Bryophytes from the Fiji Islands, IV. The genus Frullania Raddi (Jungermnniopsida), I., with description of F. vivipara Pócs, spec. nov. Fieldiana Botany 47: $147-158$.

Pócs T. 2008. Prelimininary studies on the cyanobacteria layer of transylvanian mountains (Előmunkálatok az Erdélyi Szigethegység mészkő-sziklalakó cyanobaktérium bevonatain). Kitaibelia 13(1): 126.

Pócs T. \& CAIRNS A. 2008. Contributions to the bryoflora of Australia, III. The genus Jubula Dumort., with the description of $J$. hutchinsiae Hook. subsp. nov. australiae (Jubulaceae, Jungermanniopsida). Nova Hedwigia 86(1-2): 231-236.

Pócs T., van ZANTen B. O. \& ERzBerger P. 2008. Entodon concinnus (De Not.) Paris in Hungary. Journal of Bryology 30: 163 .

SAss-Gyarmati A., Goia I. \& PÓcs T. 2008. The distribution of Metzgeria violacea in the Apuseni Mountains (Romanian Western Carpathians). Folia Cryptogamica Estonica 44: $121-124$.

\section{9}

Csintalan Zs., Pócs T. \& Tuba Z. 2009. Vegetative drought stress strategies of plants (Növények vegetatív kiszáradástürési stratégiái). Botanikai Közlemények 96: 19-21.

GÁNTI T., Pócs T., BÉrCZI Sz., HorvÁth A., KereszTuri Á., SIK A. \& SZATHMÁRY E. 2009. Ideal microhabitats on Mars: the astrobiological potential of polar dunes. In: 40th Lunar and Planetary Science Conference, The Woodlands, Texas, United States of America, 23-27 March 2009, Paper 1618. http://www.lpi.usra.edu/meetings/lpsc2009/ pdf/1618.pdf

Hentschel J., von Konrat M. J., Pócs T., SchÄFer-VerWIMP A., SHAW A. J., SCHNEIDER H. \& HEINRICHS J. 2009. Molecular insights into the phylogeny and subgeneric classification of Frullania Raddi (Frullaniaceae, Porellales). Molecular Phylogenetics and Evolution 52: 142-156.

Horváth A., Kereszturi Á., Bérczi Sz., Sik A., Pócs T., GÁNTI T. \& SZATHMÁRY E. 2009. Analysis of dark albedo features on a southern polar dune field of Mars. Astrobiology 9(1): 90-103.

Kereszturi Á., Bérczi Sz., Horváth A., Pócs T., SiK A. \& SZATHMÁRY E. 2009. Northern and southern seepages on Mars and their astrobiological consequences. In: $E u$ ropean Planetary Science Congress, Potsdam, Germany, 
13-18 September 2009, EPSC2009-445. http://meetings. copernicus.org/epsc2009/abstracts/EPSC2009-445.pdf.

Kereszturi A., Horvath A., Sik A., Kuti A., Berczi Sz., Ganti T., Pócs T., Szathmary E. 2009. Possible liquidlike water produced seepage features on Mars. In: 40. Lunar and Planetary Science Conference, Houston, United States of America, 21-28 March 2009, p. 1111. http://www. 1pi.usra.edu/meetings/lpsc2009/pdf/1111.pdf.

Ochyra R., Pócs T. \& BednAREK-Ochyra H. 2009. New national and regional bryophyte records, 21. Campylium polygamum (Schimp.) Lange \& C.O. Jensen. Journal of Bryology 31(2): 133.

Pócs T. 2009. A trópusi szigethegyek növényzetének ökológiai kutatása. Botanikai Közlemények 96(1-2): 29-30.

Pócs T. 2009. Cololejeunea (Spruce) Schiffner [Syn.: Aphanolejeunea Evans]. In: S. R. GRADSTEIN \& A. L. ILKIU-BORGES (eds), Guide to the plants of Central French Guinea. Liverworts and hornworts. Memoirs of the New York Botanical Garden 76(4): 68-78.

Pócs T. 2009. Cyanobacterial crust types, as strategies for survival in extreme habitats. Acta Botanica Hungarica 51(1-2): 147-178.

Pócs T. \& Bernecker A. 2009. Overview of Aphanolejeunea (Jungermanniopsisda) after 25 years. Polish Botanical Journal 54(1): 1-11.

Sass-Gyarmati A., Molnár K., Orbán S., Pócs T. \& ErZBERGER P. 2009. The cryptogamic flora of the Zgurăşti Sinkhole System and its surroundings. (Apuseni Mountains, Romania). Kanitzia 16: 25-44.

SCHÄFER-VERWIMP A. \& PÓCS T. 2009. Contribution to the hepatic flora of the Dominican Republic, West Indies. Acta Botanica Hungarica 51(3-4): 367-425.

\section{0}

Ah-Peng C., Bardat J., Ellis L. T., Hedderson T. A. J., MAlombe I., Matcham H., Pócs T., Porley R., SÉNECA A., SÖDERSTRÖM L. \& WiLBRAHAM J. 2010. Additions to the bryoflora of Réunion Island 3: new and interesting records from the Tropical Bryology Group (British Bryological Society). Journal of Bryology 32: 288-295.

EGGERS J. \& PÓCS T. 2010. Epiphylle Lebermoose aus Samoa: Auf den Spuren von Eduard Graeffe in der Farn-Abteilung des Herbarium Hamburgense. Berichte des Botanischen Vereins zu Hamburg 25: 3-11.

Horváth A., Bérczi Sz., Kereszturi Á., SiK A., Pócs T. \& SzATHMÁRY E. 2010. Gradual extension of Dark Dune Spots in the vicinity of spiders at the Inca City region on Mars. In: 33rd NIPR Symposium on Antarctic Meteorites, Tokyo, Japan, 8-9 June 2010. http://yamato.nipr.ac.jp/ AMRC/symposium/2010/abstracts/Horvath.pdf.

Horváth A., Bérczi Sz., Kereszturi Á., Pócs T., SiK A. \& SZATHMÁRY E. 2010. Shielding with Martian snow: suitable temperature and water vapor for possible living organisms. In: 38th COSPAR Scientific Assembly, Bremen, Germany, 18-25 July 2010, F34. https:/www.cospar-assembly.org/abstractcd/OLD/COSPAR-10/abstracts/data/ pdf/abstracts/F34-0022-10.pdf.

Hylander K., Pócs T. \& Nemomissa S. 2010. Liverworts of southwest Ethiopian montane forests: ecological and biogeographical notes. Journal of Bryology 32: 92-100.

Kereszturi A., Bérczi Sz., Horváth A., Pócs T., SiK A. \& SZATHMÁRY E. 2010. Astrobiological characteristics and possibility of life in the polar dark dune spots of Mars. In: R. B. Hoover, G. V. Levin, A. Y. RozAnOV \& P. C. W. DAVIES (eds), Proc. SPIE 7819, Instruments, Methods, and Missions for Astrobiology XIII, 78190K. http://dx.doi. org/10.1117/12.862839.

Pócs T. 2010. East African bryophytes, XXVI. New records from Mayotte (Maore) Island (French Comoro). Acta Bryolichenologica Asiatica 3: 105-114.

Pócs T. 2010. Myriocoleopsis in Southeast Asia. Tropical Bryology 31: 123-125.

Pócs T. 2010. On some less known Lejeunea (Lejeuneaceae, Jungemanniopsida) species in tropical Africa. East African bryophytes, XXVII. Nova Hedwigia Beihefte 138: 99-116.

VON KonRAT M., HeNTSChEl J., HeINRICHS J., BRAGGINS J. E. \& Pócs T. 2010. Forty-one degrees below and sixty years in the dark: Frullania sect. Inconditum, a new section of Australasian Frullania species including F. colliculosa, sp. nov., F. hodgsoniae, nom. and stat. nov., F. aterrima, and $F$. hattorii (Frullaniaceae, Marchantiophyta). Nova Hedwigia 91(3-4): 471-500.

\section{1}

Kereszturi Á., Bérczi Sz., Horváth A., Pócs T., SiK A. \& SZATHMÁRY E. 2011. Dark Dune Spots as favorable locations for brine formation on Mars. In: EGU General Assembly Vienna, Austria, 3-8 April 2011. Geophysical Research Abstracts 13: EGU2011-7353. http://meetingorganizer.copernicus.org/EGU2011/EGU2011-7353.pdf.

LeE G. E., Pócs T., Damanhuri A. \& LATiFf A. 2011. Lejeunea gradsteinii (Lejeuneaceae), a new liverwort species from Mt. Kinabalu, Sabah. Acta Biologica Plantarum Agriensis 1: 29-36.

Malombe I., Fischer E. \& Pócs T. 2011. Cheilolejeunea ulugurica (Lejeuneaceae, Marchantiophyta), a new species from Tanzania. Acta Biologica Plantarum Agriensis 1: $23-28$.

Müller F., Pócs T. \& SHevock J. R. 2011. Additions to the liverwort and hornwort flora of São Tomé and Príncipe. Tropical Bryology 33: 19-22.

Péli E. R., Nie L., Pócs T., LAufer Zs., Porembski S. \& TUBA Z. 2011. Ecophysiological responses of desiccation-tolerant cryptobiotic crusts. Central European Journal of Biology 6(5): 838-849. 
Pócs T. 2011. Preface. Acta Biologica Plantarum Agriensis 1: 5 .

Pócs T. 2011. Bazzania orbanii (Lepidoziaceae), a new species from Madagascar. East African bryophytes, XXVIII. Acta Biologica Plantarum Agriensis 1: 15-22.

Pócs T. 2011. What is Cladolejeunea Zwickel? New or little known epiphyllous liverworts, XV. Acta Biologica Plantarum Agriensis 1: 53-62.

Pócs T. 2011. East African bryophytes XXIX. The Ceratolejeunea (Lejeuneaceae) species in the Indian Ocean islands. Polish Botanical Journal 56(2): 131-153.

Pócs T. 2011. New or little known epiphyllous liverworts, XIV. The genus Colura (Lejeuneaceae) in São Tomé Island, with the description of Colura thoméensis sp. nov. Bryologist 114(2): 362-366.

Pócs T. 2011. Preface. In: Z. TuBA, N. G. Slack \& L. R. STARK (eds), Bryophyte ecology and climate change, pp. 17-21. Cambridge University Press, London.

Pócs T. 2011. Signs of climate changes in the bryoflora of Hungary. In: Z. TUBA, N. G. SLACK \& L. R. STARK (eds), Bryophyte ecology and climate change, pp. 359-370. Cambridge University Press, London.

Pócs T. 2011. Type studies of some African Lejeuneaceae. Acta Botanica Hungarica 53(1-2): 181-192.

Pócs T. \& PIIPPO S. 2011. Bryophyte flora of the Huon Peninsula, Papua New Guinea. LXXIV. Cololejeunea (Lejeuneaceae, Hepaticae). Acta Bryolichenologica Asiatica 4: 59-137.

Pócs T., Sass-Gyarmati A., Naikatini A., Tiwawa M, Braggins J., Pócs S. \& VON KonRat M. 2011. New liverwort (Marchantiophyta) records for the Fiji Islands. Telopea 13: 455-454.

Söderström L., Hagborg A., Pócs T., SAss-Gyarmati A., Brown E., VON KonRAT M. \& RENNER M. 2011. Checklist of hornworts and liverworts of Fiji. Telopea 13: 405-454.

VON KONRAT M., NAIKATINI A., TUIWAWA M., SÖDERSTRÖM L., Fife A., Renner M., Brownsey P., Perrie L., HaGBORG A., Pócs T., Lumbsch H. T., Braggins J., SÉnECA A. \& BROWN E. 2011. A brief history of the cryptogams of Fiji and prospects for the future. Telopea 13: 361-374.

\section{2}

Ah-Peng C., Bardat J., Pócs T., Söderström L., StaméNOFF P., StRAsBerg D. 2012. Red List of liverworts and hornworts for Réunion (Mascarene archipelago). Phytotaxa 68: $1-23$.

Dong S., Schäfer-Verwimp A., Meinecke Ph., FeldBerg K., Bombosch A., Pócs T., Schmidt A. R., ReITNER J., SCHNEIDER H. \& HeINRICHS J. 2012. Tramps, narrow endemics and morphologically cryptic species in the epiphyllous liverwort Diplasiolejeunea. Molecular Phylogenetics and Evolution 65: 582-594.

Ellis L. T., BednareK-Ochyra H., Pócs T., SzÜcs P., BIDLÓ A.\& WOLSKI G. J. 2012. New national and regional bryophyte records, 33. Journal of Bryology 34(4): 281-291.

Erzberger P., HöHn M. \& Pócs T. 2012. Contribution to the bryoflora of Călimani Mountains in the Eastern Carpathians, Romania. Acta Biologica Plantarum Agriensis 2: 75-97.

HeInRICHS J., DONG Sh., YU Y., SChÄFER-VERWIMP A., Pócs T., Feldberg K., Hentschel J., Schmidt A. R. \& SCHNEIDER H. 2012. A 150 year-old mystery solved: Transfer of the rheophytic endemic liverwort Myriocolea irrorata to Colura. Phytotaxa 66: 55-64.

Kereszturi Á., Bérczi Sz., Horváth A., Pócs T., SiK A. \& SZATHMÁRY E. 2012. The astrobiological potential of polar dunes on Mars. In: A. HANSLMEIER, S. KEMPE \& J. SECKBACH (eds), Life on Earth and other Planetary Bodies, pp. 441-457. Springer Science + Business Media BV, Dordrecht.

Manju C. N., Pócs T., Rajesh K. P. \& Prakashkumar R. 2012. Lejeuneaceae (Marchantiophyta) of the Western Ghats, India. Acta Biologica Plantarum Agriensis 2: 127-147.

Marschall M., Dulai S. \& Pócs T. 2012. Photosynthetic activity of cyanobacteria in cryptobiotic crust. In: Workshop on Mars - Connecting Planetary Scientists in Europe, Budapest, Hungary, 5-7 June 2012, p. 18. Budapest.

Pócs T. 2012. Bryophytes from Fiji Islands, VI. The genus Cololejeunea Raddi (Jungermanniopsida), with the description of seven new species. Acta Botanica Hungarica 54(1-2): 145-188.

Pócs T. 2012. Endogenous gemmae in certain Lejeuneaceae (Marchantiophyta). The International Journal of Plant Reproductive Biology 4(2): 101-105.

Pócs T. 2012. New or little known epiphyllous liverworts, XVI. A small collection from Laos. Acta Biologica Plantarum Agriensis 2: 5-10.

Pócs T. 2012. Notes on the representatives of genus Kurzia G. Martens (Lepidoziaceae, Jungermanniopsida) in the Colombian Andes. Acta Biologica Plantarum Agriensis 2: 103-115.

Pócs T. \& NiNH T. 2012. New or little known epiphyllous liverworts, XVII. Records from the Cát Tiên National Park, southern Vietnam. Acta Biologica Plantarum Agriensis 2: 11-19.

PÓCS T. \& SCHÄFER-VERWIMP A. 2012. Cololejeunea kuciana (Lejeuneaceae, Marchantiophyta), another new species from Southern Ecuador. In: K. WoŁOWSKI, B. GoDZIK \& J. J. WóJCICKI (eds), Return to the roots. A Gedenkschrift dedicated to the memory of Marian Kuc. Polish Botanical Journal 57(1): 51-53. 
Pócs T., Brown E. A., Cairns A., Cargyll D. C. \& Pócs S. 2012. Contribution to the bryoflora of Australia III. The genus Nowellia Mitt. (Cephaloziaceae, Jungermanniopsida). Acta Biologica Plantarum Agriensis 2: 21-26.

SIMON T. \& PÓCS T. 2012. New aspects of the alpine vegetation of Parâng Mountains (South Carpathians). Journal of Plant Development 19: 99-129.

SiMON T. \& PÓCS T. 2012. Studies on the alpine vegetation of Parâng mountains, South Carpathians. In: A. I. CsATHÓ (ed.), Abstract of the 9th Recent Floristic and Vegetation
Research in Carpathian Basin, International Conference at Szent István University, 24-26th February 2012, Gödöllö, Hungary. Kitaibelia 17: 53.

VojtKó A., SAss-Gyarmati A., Pócs T. \& Dulai S. 2012. Critical assessment of the flora of the Vargyas gorge (Eastern Carpathians). Acta Biologica Plantarum Agriensis 2: $27-74$. 